\title{
Sobre el derecho constitucional y sus fundamentos (primera parte). Bases históricas de la Constitución y el Constitucionalismo ${ }^{1}$
}

\section{On the constitutional law and its foundations (First part). Historical bases of the Constitution and the Constitutionalism \\ Sobre o direito constitucional e seus fundamentos (primeira parte). Bases históricas da Constituição e Constitucionalismo}

Sur droit constitutionnel et ses fondements (première partie). Bases historiques de la constitution et du constitutionnalisme 论宪法及其基础(第一部分). 宪法与宪政的历史基础

Miguel Revenga Sánchez ${ }^{2}$ | Universidad de Cádiz

Revista Derechos en Acción ISSN 2525-1678/ e-ISSN 2525-1686

Año 4/Nº 12 Invierno 2019 (21 junio a 20 septiembre), 48-104

DOI: https://doi.org/10.24215/25251678e300

ORCID: https://orcid.org/ 0000-0002-7807-6684

Recibido: 01/07/2019

Aprobado: 01/08/2019

Resumen: En un trabajo sobre los fundamentos del derecho constitucional, rescatando las bases históricas de la constitución y el constitucionalismo el autor plantea que en la enseñanza y estudio de la materia el constitucionalista debe esforzarse por atraer la atención del alumno acerca los siguientes extremos; a ) Cuál es el significado de la Constitución como norma política en la que se encuentra el agregado de

1 El presente trabajo es el primero de una serie de tres que aparecerán publicados con carácter sucesivo en los siguientes números de 13 y 14, respectivamente, de REDEA.

2 Catedrático de Derecho Constitucional en la Universidad de Cádiz. 
ideas y concepciones que permite fundamentar un orden de convivencia democrática. b) Qué es lo que diferencia, formal y materialmente, a la Constitución del resto de las normas que integran el ordenamiento jurídico y, last but not least, y c) Cuáles son las técnicas mediante las cuales se persigue el influjo que la Constitución debería ejercer sobre el ordenamiento jurídico en su dinámica de funcionamiento efectivo.

Palabras clave: Constitución. Derecho Constitucional. Enseñanza.

Abstract: In a work about the foundations of constitutional law, rescuing the historical basis of the constitution and constitutionalism, the author states that in the teaching and study of the subject, the Constitutionalist must make an effort to attract the attention of the student on following: a) What is the meaning of the Constitution as a political norm in which the aggregate of ideas and conceptions of an order of democratic coexistence are present. b) What differentiates, formally and materially, the Constitution from the rest of the norms that integrate the legal system and, last but not least, c) What are the techniques by which the influence that the Constitution should exert is pursued on the legal system, in its dynamics of effective functioning.

Keywords: Constitution. Constitutional right. Teaching.

Resumo: Em um trabalho sobre os fundamentos do direito constitucional, resgatando as bases históricas da constituição e 0 constitucionalismo, 0 autor afirma que no ensino e estudo da matéria, o constitucionalista deve se esforçar para atrair a atenção do aluno sobre os seguintes extremos: a) Qual é o significado da Constituição como norma política na que está 0 agregado de ideias e concepções que permitem basear uma ordem de convivência democrática. b) 0 que diferencia, formal e materialmente, a Constituição do resto das normas que integram o sistema legal e, last but not least, c) Quais são as técnicas pelas quais o influxo que a Constituição deve exercer sobre o sistema legal em sua dinâmica de funcionamento efetivo é perseguido?

Palavras-chave: Constituição Direito constitucional. Ensino.

Résumé: Dans cet ouvrage sur les fondements du droit constitutionnel, sauvant le fondement historique de la constitution et du constitutionnalisme, l'auteur affirme que, dans l'enseignement et l'étude du sujet, le constitutionnaliste doit s'efforcer d'attirer l'attention de l'étudiant 
sur les extrêmes suivants; a) que signifie la Constitution en tant que norme politique regroupant un ensemble d'idées et de conceptions qui permettent fonder un ordre de coexistence démocratique? b) qu'est-ce qui différencie, formellement et matériellement, la Constitution du reste des normes qui intègrent le système juridique et; et c) Quelles sont les techniques qui poursuivent l'efficace de l'influence que la Constitution devrait exercer sur le système juridique

Mot-clés: Constitution Droit constitutionnel. Enseignement

摘要:在一部关于宪法基础的工作中, 拯救宪法和宪政的历史基础, 作者指出, 在该学科的教学和研究中, 宪政主义者必须努力吸引学 生关注以下极端; a) 宪法作为一种政治规范的含义是什么, 其中是 允许建立民主共存秩序的思想和概念的总和。b) “宪法” 与其他整合 法律体系的规范, 最后但并非最不重要的, 以及c）宪法”应施加的影 响的技术有何区别, 正式和实质上有何区别关于法律制度的有效运 作动态。

关键字: 关键字: 政治宪法, 宪法, 教学

\section{Introducción}

Hace ya bastantes años, cuando con ocasión del concurso a una plaza de profesor titular, me enfrenté a la tesitura de redactar un proyecto para la docencia en Derecho Constitucional, éste vivía un momento de transformación. Del añejo Derecho Político, las autoridades españolas en materia de enseñanza universitaria acababan de desgajar dos áreas de conocimiento que respondían básicamente a dos enfoques de la asignatura: sociológico-político el uno, centrado en la dinámica de despliegue de los procesos políticos; jurídico-formal el otro, con su punto de enfoque en las características de la Constitución como norma jurídica y en los problemas derivados de su aplicación y desarrollo.

Redacté entonces un proyecto que, releído al cabo de los años, produce cierta sensación de eclecticismo. Habiendo de concursar a una plaza del área de Derecho Constitucional, fui consciente de que la concepción de la asignatura sólo podía decantarse por el segundo de los enfoques señalados. Pero defendí, al mismo 
tiempo, que muy pocas cosas podían entenderse en nuestra asignatura si se dejaba de lado el proceso político del que, en definitiva, dependía la efectividad de la Constitución.

Mi concepto del Derecho Constitucional, y la delimitación de los contornos del área de conocimiento, reivindicaban el sincretismo, aún a costa de reflejar buenas dosis de esquizofrenia metodológica. Era consciente de lo que había que enseñar - el sistema constitucional español, que acababa de sobrepasar por entonces los diez años de vida - pero me sentía incapaz de hacerlo sin el correspondiente arsenal de conocimientos de impronta sociológica (o politológica), que consideraba imprescindible para la cabal comprensión de las categorías y los conceptos constitucionales. Que calificara la querella metodológica, entonces pujante entre nosotros (aunque el viejo Derecho Político se hubiese escindido ya de forma irremediable), como la "manifestación de un dualismo recurrente", es la muestra más evidente de lo que a la sazón creía.

Mi posicionamiento estaba imbuido de la siguiente idea central: el Derecho Constitucional es ciencia incompleta, y aún huera, sin el influjo vivificador de categorías doctrinales tomadas (¡después de tanto tiempo!) de la Teoría del Estado de impronta germana. En ella, ciencia del derecho y teoría de los procesos políticos habrían encontrado cierto equilibrio acomodaticio, además de notable consistencia lógica. Lo que pretendía justificar era acaso lo injustificable: cuánta Teoría del Estado, llamémosla así, era necesaria para comprender el significado de la Constitución en su forma externa y en su proyección efectiva. Conceptos tales como Estado, soberanía, poder constituyente o legitimidad, por mencionar algunos, me parecían no ya centrales en mi consideración general de la asignatura, sino verdaderos puntos de partida para realizar una aproximación "científica" al Derecho Constitucional digna de tal nombre.

Bastantes años adicionales de dedicación exclusiva a la enseñanza e investigación en el campo del Derecho Constitucional han variado, cuando menos parcialmente, mi modo de ver las cosas. De tal variación adquiero plena conciencia 
cuando me formulo lo que considero la pregunta clave para una correcta delimitación de los ámbitos de estudio relacionados con el Derecho Constitucional. La pregunta se refiere al lugar que debe ocupar dicha rama del saber jurídico en el conjunto de la formación de un estudiante de Derecho, y es susceptible de desdoblarse en una serie de cuestiones secundarias, cuyo planteamiento y respuesta deben actuar a modo de líneas directrices.

Simplificando un poco las cosas, podría decirse que el constitucionalista debe esforzarse por atraer la atención del alumno acerca los siguientes extremos:

a) Cuál es el significado de la Constitución como norma política en la que se encuentra el agregado de ideas y concepciones que permite fundamentar un orden de convivencia democrática.

b) Qué es lo que diferencia, formal y materialmente, a la Constitución del resto de las normas que integran el ordenamiento jurídico y, last but not least

c) Cuáles son las técnicas mediante las cuales se persigue el influjo que la Constitución debería ejercer sobre el ordenamiento jurídico en su dinámica de funcionamiento efectivo.

Todo ello con una dificultad adicional a efectos docentes: la formación básica en Derecho Constitucional se aborda, por lo general, en los momentos iniciales de los estudios de Derecho, cuando el alumno se encuentra todavía lejos de estar familiarizado con los conceptos y las técnicas propias de la ciencia jurídica, lo que convierte muchas veces la enseñanza del Derecho Constitucional en una introducción, a secas, al ámbito de lo jurídico. La tarea del constitucionalista es entonces cualquier cosa menos fácil: no sólo habrá de realizar, en esos momentos iniciales de la vida universitaria del alumno, abundantes incursiones por la filosofía política y por la historia (y aún por la filosofía de la historia), para hacer inteligible el extremo $a$ ), sino que además, y al objeto de hacerse entender en aquello que afecta a los extremos b) y c), necesitará moverse cómodamente 
en los terrenos, no siempre fáciles de transitar, de la teoría y los conceptos generales de la ciencia del Derecho.

\section{Fuerza normativa de la Constitución y constitucionalismo}

Tengo para mí que la fijación, con ribetes obsesivos, en favor de la inclusión de una Teoría del Estado que actuara a modo de exordio de los contenidos de nuestra asignatura propiamente dichos, era consecuencia de cierta actitud indecisa en cuanto al método. Una indecisión que venía acompañada de problemas relativos a la búsqueda de un espacio académico propio, como consecuencia de circunstancias históricas bien conocidas: la "huída" de una realidad en la que no tenían encaje posible las categorías constitucionales construidas en nuestro entorno sociopolítico, lo que llevaba a compensar el déficit de juridicidad - consecuencia del caudillismo autoritario que alentaba el sistema - con construcciones etéreas, que permitían dar cierto empaque teórico a la disciplina, echando tierra (como no fuera por la vía indirecta de la comparación) sobre las miserias y peculiaridades del régimen autoritario.

La Teoría del Estado explicada al modo decimonónico, según el modelo de los grandes tratadistas germanos (la célebre linea Gerber-Laband-Jellinek viene de inmediato a la cabeza), y el "institucionismo" de impronta franco-italiana, con Hauriou y Santi Romano como nombres de rigor, permitían dar apariencia de sistema, de "ciencia" incluso, al "universal comodín" sobre el que ironizara Don Nicolás Ramiro Rico, uno de los nombres ineludibles cuando se trata de reflexionar sobre el tortuoso devenir de nuestra disciplina durante el franquismo ${ }^{3}$.

Varias décadas de tradición académica no pasan en balde. La resistencia a abandonar viejos enfoques, vigente ya la Constitución de 1978, vino a llamar la atención acerca de la necesidad de asentar nuestra disciplina sobre bases más sólidas que las de la mera glosa positivista de los preceptos constitucionales,

3 Nicolás Ramiro Rico, El animal ladino y otros Estudios políticos, Madrid, Alianza, 1980. 
aplicados e interpretados por los órganos jurisdiccionales, con el Tribunal Constitucional, en tanto que supremo intérprete, situado a la cabeza de ellos.

La conocida polémica metodológica de los primeros años 80 del pasado siglo entre los profesores Eduardo García de Enterría y Pablo Lucas Verdú podría aducirse como botón de muestra del momento en el que el Derecho Político experimentaba un proceso de decantación hacia el Derecho Constitucional, y el Derecho Constitucional se mostraba renuente a dejar de ser Político $^{4}$. A uno y otro profesor debemos muchos de los que entonces comenzábamos a profundizar en el estudio de la asignatura la reafirmación de una curiosidad intelectual cuyos caminos se nos antojan hoy perfectamente complementarios: uno centrado en la tradición constitucional norteamericana, y orientado hacia la aplicación jurisdiccional de la Constitución; el otro, insistiendo en la dimensión cultural y valorativa de nuestra disciplina, con su punto de inflexión en las grandes aportaciones doctrinales de la Alemania de Weimar.

A más de treinta años de distancia, comparar la referida polémica con otros debates más recientes, como por ejemplo los relativos al instituto del amparo, la funcionalidad del Senado, o el cada vez más acuciante sobre la propia conveniencia de abrir la espita de la reforma constitucional, son un excelente indicio para calibrar la evolución del Derecho Constitucional en el seno de nuestra comunidad científicas 5

4 Eduardo García de Enterría, La Constitución como norma y el Tribunal Constitucional; Madrid, Cívitas, 1981; Pablo Lucas Verdú, “El Derecho Constitucional como Derecho Administrativo (La 'ideología constitucional' del profesor García de Enterría”, Revista de Derecho Político, 13 (1981), pp. 7 y ss.; Eduardo García de Enterría, “El Derecho Constitucional como Derecho", Revista de Derecho Político, 15 (1982), pp. 7 y ss. Y más recientemente, véase, Pablo Lucas Verdú, “Una polémica obsoleta o una cuestión recurrente?: Derecho Constitucional versus Derecho Político", Teoría y Realidad Constitucional, 3 (1999), pp. 55 y ss. Los ecos de la polémica aún resuenan en las respuestas a la Encuesta sobre la orientación del Derecho Constitucional que publicó la propia Teoría y Realidad Constitucional, 21 (2008).

5 Remito, por todos, a los trabajos de Peces Barba, Pérez Royo y Cascajo Castro, publicados en Claves de Razón Práctica, 138 (2003), con ocasión del vigésimo quinto aniversario de la Constitución española de 1978. 
El Derecho Constitucional, digámoslo ya, puede quitarse de encima cualquier complejo que pudiera derivarse de hipotéticos déficits epistemológicos padecidos en el pasado. Bajo el influjo de una Constitución democrática que ya ha superado holgadamente las tres décadas de vida, bastantes miles de páginas de aportaciones doctrinales, y algunas decenas de tomos de jurisprudencia constitucional, atestiguan que en España el oficio de constitucionalista, y la ciencia del Derecho Constitucional, se integran en un sistema del todo equiparable al oficio y la ciencia cultivado, bajo el mismo nombre, allende nuestras fronteras, a este y a aquel lado del Atlántico. La razón es bien pedestre, pero basta por sí sola para quitar sentido al empeño de continuar explorando los supuestos arcanos del método. Una disciplina tan asentada como la nuestra no necesita proclamar, para convencer no se sabe a quién, que el Derecho Constitucional avanza por la senda del cientifismo gracias al empleo del método dicho jurídico. Porque teniendo, como tenemos, una Constitución normativa, ¿qué otra cosa, sino método jurídico, podría emplearse para afrontar los problemas planteados, lege data o lege ferenda, por una norma, todo lo peculiar que se quiera, pero norma al cabo, como la Constitución?

Hacer Derecho Constitucional con un mínimo de rigor científico no es cuestión de sincretismos metodológicos ni de mixturas, sino un problema de tomar en serio la "fuerza normativa de la Constitución" (según la feliz expresión de Konrad Hesse), extrayendo de ella las consecuencias que procedan. Esto resulta hoy una obviedad, pero conviene tenerlo presente cuando se trata de reflexionar sobre el núcleo de las concepciones que alumbran la propia visión de la asignatura, condicionando de manera decisiva la disposición de materiales de conocimiento en que cualquier programa, o plan para la acción docente, consiste.

La fuerza normativa de la Constitución no surge del vacío. La normatividad constitucional presenta una dificultad intrínseca que proviene tanto del elevado nivel de abstracción y generalidad de las prescripciones, como de sus propias fuentes normativas. En el punto de intersección entre la política y el 
Derecho - política que se normativiza, y norma que aspira a una regulación de lo político - la Constitución afronta siempre el riesgo de ver socavada su fuerza directriz a manos de actores particularmente poderosos, y con tendencia a presentar resistencia a la vocación limitadora/encauzadora del poder que toda norma, y particularmente la Constitución, conlleva.

Dicha dificultad, históricamente persistente, aún cuando el decurso del Estado constitucional haya caminado hacia una superación (siempre imperfecta y parcial) de la misma, es la que obliga a rastrear los momentos constitucionales del pasado. La idea presente de Constitución procede de ellos, como también tales momentos son hijos de circunstancias políticas que no deben olvidarse. El Derecho Constitucional y el concepto de Constitución que hoy profesamos se han ido haciendo sobre la base de afirmaciones y negaciones, de utopías que aspiraban a tomar cuerpo y resistencias que tomaban del pasado su capacidad de obstruir y "rebajar" en la práctica, hasta hacerlos irreconocibles, los elevados objetivos plasmados en el documento constitucional.

Todo ello necesita desde el punto de vista didáctico de una teoría que aporte, como lo hace cualquier teoría, cierta ilusión de coherencia, un hilo conductor capaz de revelar, con sus persistencias y discontinuidades, una lógica, fragmentaria y parcial si se quiere, pero lógica al fin, que haga inteligible la realidad presente - el Estado constitucional y democrático - desde la perspectiva de los avatares del pasado. Dicha teoría y dicha lógica, más que centrarse en el Estado - al fin y al cabo una mera forma de organización sometida, como lo apreciamos hoy espectacularmente, a la erosión del tiempo - debería ser construida, a nuestro juicio, desde el otro polo del binomio "Estado Constitucional", es decir, desde la continuidad de ciertos rasgos culturales previos, sin duda más etéreos que aquella organización que tomó realidad corpórea al derrumbarse el mundo del medievo. Me refiero a la idea de constitucionalismo, una idea - ideología, si se quiere - que cuenta en su favor con la fascinación de lo simple: la limitación del poder para garantizar espacios de libertad, 
y que probablemente por ello permite reconstruir, ordenar y unificar realidades históricas plurales, analizándolas bajo el prisma de un concepto de significado polivalente y cambiante, el de Constitución, y de una ideología, el constitucionalismo, cuya aspiración central es justamente llenar dicho concepto de una significación precisa.

En las páginas que siguen intentamos trazar un itinerario, de los muchos posibles, a través de los avatares de este concepto y de aquella idea. Y ello no con la intención de arrojar luz sobre el fondo de unas cuestiones sobre las que es difícil eludir la impresión de que ya está todo dicho, sino simplemente con el propósito de mostrar, haciendo explícita nuestra personal selección del recorrido, cuáles son los fundamentos o presupuestos de los que partimos a la hora de programar la enseñanza (y profundizar en el estudio) del Derecho Constitucional.

\section{Gobierno limitado y Constitucionalismo antiguo}

El término "constitucionalismo" comparte, como se ha dicho, idénticas características a las que son propias de muchos "ismos": no tiene un significado claramente descriptivo ni prescriptivo; sus contornos no son fáciles de discernir, y sus raíces históricas son inciertas y de la más diversa naturaleza. Con tales observaciones genéricas comienza Casper su glosa del término para la Encyclopedia of American Constitution ${ }^{6}$. Walton Hamilton, un defensor del realismo jurídico y autor de la misma voz en una obra más clásica, la Encyclopedia of the Social Sciences, arranca, por su parte, con vena irónica: "constitucionalismo es el nombre con el cual designamos la confianza que los hombres depositan en el valor de unas palabras recogidas en un pergamino para limitar el poder de los gobernantes" 7 .

\footnotetext{
6 Gerhardt Casper, “Constitutionalism”, en L. Levy, K. Karst y D. Mahoney, (eds.), Encyclopedia of the American Constitution, Nueva York, MacMillan, 1986, vol 2, pp. 473 y ss.

7 Walton Hamilton, "Constitutionalism”, en E. A. Selidman et al. (eds.), Encyclopedia of the Social Sciences, Nueva York, MacMillan, 1931, pp. 255 y ss.
} 
Uno y otro enfoque parecen ser deudores de puntos de vista distintos en torno al valor último de la idea constitucional. El primero da cuenta de la complejidad de la idea, y defiende la necesidad de mirar al pasado para alcanzar alguna certidumbre. El segundo opera mediante una simplificación reductora, y parece estar pensando exclusivamente en un significado prescriptivo de Constitución, entendida al estilo "de los modernos".

Quizá una aproximación de naturaleza filosófica al vocablo "constitución" pueda tener alguna utilidad para seguir adelante. La voz "constitución", nos dice Ferrater Mora en su magno Diccionario de Filosofía, arrastra significados muy diversos que, aunque centrados en la acción del fundar, oscilan entre la creación y la simple ordenación de lo dado. Ferrater se apoya extensamente en las ideas de Rudolf Carnap, el miembro del Círculo de Viena y autor de una teoría de la constitución de los conceptos, cuyo objetivo fue desbrozar el camino para superar la mencionada bifurcación de significados, entre "engendrar" y "ser conocido". El hecho de constituir debe ser considerado, a juicio de Carnap, desde un punto de vista puramente neutral y utilizando un lenguaje neutral que no prejuzgue cuestiones de índole metafísica. "La finalidad de la teoría de la constitución - escribe Carnap - consiste en la edificación de un sistema de objetos (o conceptos) ordenados de acuerdo con diferentes grados; el orden gradual está determinado, a su vez, por el hecho de que los objetos de cada grado están constituidos a

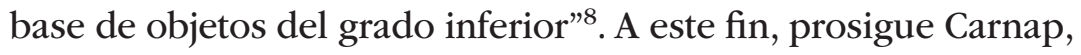
es preciso abordar cuatro problemas fundamentales:

- elegir un punto de partida, un primer grado sobre el que puedan fundarse los demás (problema de la base del sistema).

- determinar las formas recurrentes dentro de las cuales se realiza el paso de un grado al siguiente (problema de la forma gradual).

8 Der logische Aufbau der Welt, cit. en José Ferrater Mora, Diccionario de Filosofía, Madrid, Alianza, 1979, vol. I, p. 610. 
- investigar de qué modo son constituidos los objetos de diferentes especies por la aplicación gradual de las formas (problema de las formas objetivas).

- precisar la forma general del sistema (problema de la forma del sistema).

Con lo cual, apostilla el autor de La construcción lógica del mundo, constituir equivale, en el fondo, a reducir.

Es esta conclusión apodíctica la que nos interesa destacar a los efectos de poder sentar, muy someramente, alguna idea relativa a la supuesta impronta constitucionalista de las formas políticas del mundo clásico y del medioevo.

La polémica sobre la existencia de un hipotético constitucionalismo "antiguo" cobró cierto auge entre nosotros a propósito de la difusión del libro de Charles H. McIlwain, Constitucionalismo antiguo y moderno. La traducción española, anunciada y esperada por espacio de años, contribuyó a poner sobre el tapete una serie de tópicos del pensamiento constitucional cuyo sentido evoca el que deja traslucir la célebre conferencia dictada en 1819 por Benjamin Constant, con el título De la liberté des modernes comparée à celle des antiques. En uno y otro caso, los autores operan por reducción buscando un fundamento último de los casos estudiados; fundamento que no responde a una lógica inmanente a éstos, sino que se descubre gracias a una interpretación trascendente del pasado que, desde el respectivo tiempo presente de ambos autores, viene a iluminarlo con las luces constitucionales ${ }^{9}$. Un constitucionalismo moderno, con Constitución escrita, como reducción racional o acto de voluntad plenamente consciente, propicia así la interpretación compendiada del pasado en clave constitucional.

En el mundo griego, verdadero vivero de lo que hoy llamaríamos una ingeniería constitucional pródiga en recursos, tres

\footnotetext{
9 Cfr. la Introducción, a cargo de Giovanni Paoletti, a Benjamin Constant, La libertà degli antichi parangonata a quella dei moderni, Turín, Einaudi, 2001, con un enjundioso Epílogo, "Profilo del liberalismo", de Pier Paolo Portinaro.
} 
nombres insignes vienen de inmediato a la cabeza. El primero es el de Solón, y su Carta para regir la ciudad-estado de Atenas. La tiranía como forma de gobierno, imperante en las diversas ciudades hasta los siglos VIII y VII a.C., y el predominio de la aristocracia, se ven allí atemperados mediante la creación de una asamblea del pueblo (Ekklesia), competente para la decisión de las cuestiones fundamentales, así como por la de un tribunal popular (Heliaia), llamado a dirimir los conflictos relativos a la forma en que se desempeñaban las funciones públicas.

El segundo de los nombres ineludibles a la hora de buscar precedentes remotos del empeño constitucionalista es el de Platón. Su Diálogo El Politico, en efecto, ha sido a menudo presentado como la primera reflexión profunda sobre la relación entre el poder político y la ley. El tema central de dicho Diálogo es, como es sabido, el de las ventajas e inconvenientes de sujetar el poder mediante la operatividad de la ley. El gobierno limitado se presenta como una especie de forma indecisa - el puente con la crítica de Carl Schmitt al parlamentarismo resulta evidente - en el que el principio de prevenir que el Gobierno haga demasiado mal es, al propio tiempo, la rémora que obstaculiza hacer el bien. ¿Conviene renunciar al bien para prevenir el mal, o es preferible someterse al mal para asegurar el bien? Consideraciones de este género son las que inducen a Platón a defender como forma perfecta de gobierno aquella fundada sobre la discreción del gobernante, y no sobre la ley. Su reivindicación del filósofo-rey, capaz de hacer de su arte una ley, viene a ser así el precedente más clásico del pensamiento político favorable a un poder regio fuerte y centralizado.

El nombre de Aristóteles completa, en fin, la tríada griega que queríamos traer a colación. Verdadero fundador de la ciencia de la política, la aportación del estagirita no es sólo fundamental en materia de formas de gobierno, sino además, en lo que a nosotros nos afecta, porque aporta una definición sumarísima de un término, el de Politeia, que comienza a traducirse, al menos desde el siglo XVIII, como constitución. "Una constitución - se lee en el Capítulo VI del Libro Tercero de La 
Politica - es la ordenación de las distintas magistraturas de la ciudad, y especialmente de la suprema" ${ }^{10}$.

Una definición ésta que es consecuente con lo que Sartori llama la "dimensión vertical de la política", y en la que se echa clamorosamente en falta lo que el cristianismo, la Reforma, el racionalismo iusnaturalista y el iluminismo añadirían posteriormente: el valor de lo individual ${ }^{11}$.

Desde la perspectiva constitucionalista, quizá el valor de las experiencias de la Roma republicana, y del Imperio, radica precisamente en el descubrimiento del protagonismo del individuo en la escena política. De la mano del estoicismo, el pensamiento político comienza, en efecto, a aclarar dos ideas y a entremezclarlas en un esquema común de valores: la idea de individuo como ejemplar único e irrepetible de la especie humana con vida personal y privada, y la idea de universalidad de una humanidad que alcanzaba a todo el mundo, y en la que todos los hombres estaban dotados de una naturaleza que compartían. En el nuevo universo conceptual, la igualdad deja de estar supeditada a la ciudadanía en el marco territorial de la ciudad-estado. La libertad dejará también de ser atributo de la ciudadanía para convertirse en elemento ontológico del ser humano.

En el pensamiento estoico, como expone Sabine, por encima de la diversidad de la costumbre, la ley superior de la razón debería ser común a todas las ciudades y su acatamiento vendría a evitar la oposición de las costumbres, aunque no su diversidad $^{12}$. Puede afirmarse así que la creación de un orden

\footnotetext{
10 Aristóteles, La Política, edición de Julio Pallí, Barcelona, Bruguera, 1974, p. 132.

11 Cfr. Giovanni Sartori, Teoría de la democracia, Madrid, Alianza, 1987, vol. 2 (“Los problemas clásicos"), Cpt.X (“La democracia griega y la democracia moderna”), donde es claro el influjo de Isaiah Berlin, sobre todo de Two Concepts of Liberty, con la diferenciación que, a su vez, está en la obra de Constant antes citada, entre la libertad negativa (la de los modernos, "hecha del pacífico goce de la independencia privada") y la libertad positiva de los antiguos, "basada en la participación activa y constante en el poder colectivo".

12 Por si a alguien le extrañara la aparición, en este contexto, del libro de Sabine que enseguida citaré, no resisto el impulso de recordar aquí que tal libro lo fue de texto en la asignatura llamada entonces Derecho Político del primer Curso de la licenciatura, en la
} 
jurídico mundial fue una de las pretensiones de los estoicos, en coherencia con su idea de una comunidad universal, sobre la base de la razón que es la ley de la naturaleza ${ }^{13}$. El puente con la actual aspiración cosmopolita, revivificadora de tales ideas por la vía del Kant de La pazperpetua, es también aquí evidente.

Los nombres de Polibio y Cicerón resultan inexcusables en esta sumarísima incursión por el pensamiento de interesada (por nuestra parte) impronta "constitucionalista". El primero, verdadero mentor de la ciencia de la comparación, es célebre por su conocida teoría de la sucesión de las constituciones. Según él, las sociedades conocen necesariamente, entre cataclismos cíclicos en los que toda civilización resulta aniquilada, la siguiente evolución: la monarquía, estado inicial que se define por la adhesión natural al más fuerte, se transforma en realeza, que es una monarquía moralizada en la que el poder de un soberano justo se funda en la libre adhesión. La realeza degenera en tiranía cuando el rey cede al impulso de sus pasiones; la tiranía es destruida por la sublevación de los mejores, a quienes el pueblo, en recompensa, confía el poder, fundándose de esta forma una aristocracia que, debido a la intemperancia de las siguientes generaciones de aristócratas, se transforma en oligarquía. La rebelión popular da origen entonces a la democracia, devota de la libertad y la igualdad, pero la ambición de algunos (sobre todo de los ricos) corrompe al pueblo: crisis, luchas entre facciones, proscripciones y matanzas serán el inevitable corolario generador de la catástrofe cuyo resultado será la monarquía que reinicia el ciclo.

Facultad de Derecho de la Universidad Complutense de Madrid durante el "juliano" Año académico, que duró de enero a junio de 1974, siendo responsable del grupo, si mi memoria no me traiciona, el hoy catedrático en la Universidad Autónoma, Juan José Solozábal. Manejo ahora el mismo ejemplar, ya ajado, con el que descubrí entonces que el universo de lo político se componía de bastantes más cosas de lo que la casposa retórica del tardofranquismo dejaba entrever.

13 George Sabine, Historia de la teoría política, México, Fondo de Cultura Económica, 1974, Cpt. VIII ("El Derecho Natural”). 
Como ya había visto Aristóteles, el gobierno ideal ha de basarse en una combinación de formas capaz de generar un equilibrio a través del juego de fuerzas contrarias. Según Polibio, legitimador de la expansión imperial, semejante ideal se habría alcanzado en Roma, cuya Constitución satisface la exigencia indicada. Los poderes de los cónsules hacían pensar en una realeza; los del Senado, en una aristocracia, y los del pueblo, a través de los comicios, en una democracia.

Cicerón, por su parte, comparte el sólito entusiasmo por el gobierno mixto, pero el interés de su obra, a nuestros efectos, radica en la actualización de la doctrina estoica de un derecho natural avant la lettre, llevada a cabo por el mismo, y que alcanzaría notable influjo a lo largo de los siglos. Según Cicerón, hay un derecho natural universal que surge a la vez del providencial gobierno del mundo por Dios, y de la naturaleza racional y social de los seres humanos que les hace afines a Dios. Este derecho universal es el mismo en todas partes y obliga mutuamente a todas las naciones. Ninguna legislación que lo infrinja merece el nombre de ley, porque ningún gobernante ni pueblo puede convertir lo injusto en justo, y viceversa ${ }^{14}$.

De aquella ley universal de la naturaleza surge la igualdad como una exigencia moral, aunque no exista de hecho y, del mismo modo, la con-ciudadanía en la que todos los hombres viven supone ciertos rasgos comunes entre ellos. Para Cicerón, esto no desemboca en una preferencia por la democracia: "la igualdad de derecho o la democracia es una quimera imposible, y los pueblos más enemigos de toda dominación y todo yugo han conferido los poderes más amplios a algunos de sus elegidos, fijándose con cuidado en la importancia de los rangos y en el mérito de los hombres”. Pero sí avala la exigencia de una dignidad común para todos los hombres, que incluye a los esclavos.

De ese axioma de la dignidad común se desprenden consideraciones fundamentales sobre la concepción, que pudiéramos

14 Cfr. Sabine, Historia de la teoría política, Cpt. IX ("Cicerón y los Jurisconsultos romanos”). 
llamar juridicista del poder. Una República no puede perdurar, o lo hará en malas condiciones, a menos que se base en la conciencia de las obligaciones recíprocas y el mutuo reconocimiento de los derechos que vinculan a los ciudadanos entre sí, llevando a la práctica las consecuencias de esta conciencia. "Es la República - escribe - cosa del pueblo, considerando como tal no a todos los hombres de cualquier modo congregados, sino a la reunión que tiene su fundamento en el consentimiento jurídico y en la común utilidad (...). La libertad no puede existir verdaderamente sino allí donde el pueblo sabe mantener sus prerrogativas (...). Sólo entonces es la cosa pública cosa del pueblo".

Con todas las salvedades relativas a un concepto de pueblo que poco tiene que ver con el que sustentará las doctrinas revolucionarias de la época contemporánea, quizá pueden presentarse tales postulados ciceronianos como la síntesis de la aportación romana al acervo del constitucionalismo antiguo. A semejanza de la lex, como contrato entre individuos privados, cuya fuerza radica en el consentimiento (sponsio) de los contratantes, la lex publica será presentada como un convenio de todos, conforme expresa el célebre brocardo lex est comunis reipublicae sponsio.

El sponsio, como esencia misma del viejo contrato inter privatos, trasciende así el ámbito de lo privado, para erigirse en principio político fundamental, dando lugar a la imagen, en pugna con el absolutismo del príncipe, de que el populus es la fuente última de la autoridad política. Un autor como Corwin, interesado en rastrear los orígenes de la idea de Higher Law y su influencia en la construcción norteamericana de la judicial review, enfatiza la importancia de la obra de Cicerón, desde una doble perspectiva. En primer lugar, debido a la insistencia del filósofo romano en un derecho natural no necesitado de más intérprete que el propio individuo. De ahí se seguirá la presentación de la ley contraria a la Constitución como una ley inconstitucional per se, y no porque la autoridad conferida a los Tribunales así lo declare. En segundo término, por la descripción del juez, presente en De legibus, como "boca de la ley" (magistratum legem esse loquentem, legem autem mutum 
magistratum), una imagen persistente en los escritos de Coke o Montesquieu, que continúa deslumbrándonos ${ }^{15}$.

Las representaciones políticas de la Edad Media aparecerán así marcadas por la contraposición entre lo que el Rey puede hacer sobre la base de su sola voluntad, y aquello que, por formar parte del derecho inmemorial de los súbditos, resulta vedado a la acción unilateral (en el sentido de no consentida) del monarca.

La obra del inglés Henry of Bracton, juez él mismo durante el reinado de Enrique III (1216-1272), debe su reputación al hecho de estar basada en una recopilación de más de 2.000 decisiones judiciales. El análisis de éstas permite al autor poner en contacto el emergente common law de la época, con el Derecho Romano y con las ideas medievales relativas a la vigencia de un derecho superior, al que el rey debe acatamiento. "El Rey - se lee en un pasaje del Tratado de Bracton, muy a menudo citado - no debería estar sujeto a los hombres, sino sujeto a Dios y a la ley, puesto que es la ley la que instituye al Rey. Permitamos, pues, al Rey atribuir a la ley lo que la ley le concede, singularmente dominio y poder, pues no hay Rey allí donde impera la voluntad, no la ley".

Tales palabras de Bracton reflejan a la perfección el concepto, plenamente vigente, al menos en la baja Edad Media, de que toda autoridad deriva de la ley, y se halla, en consecuencia, limitada por ella. A ese respecto nos recuerda Matteucci que El Gobierno limitado se representa en la iconografía medieval mediante un Rey que porta en una mano la espada y en la otra un libro.

"A un Rey que gobierna rectamente - dirá Bracton - le son necesarias estas dos cosas: las armas y las leyes". Las armas para combatir contra los enemigos exteriores y los rebeldes internos que amenazan la tranquilidad del reino; las leyes, para mantener una situación de paz, basada en la justicia, entre los súbditos. En

15 Edward Corwin, The Higher Law Background of American Constitutional Law, Ithaca, Cornell University Press, 1955, p. 14. 
tal dicotomía aparece implícita la distinción entre gubernaculum y iurisdictio, en la que tanto insisten autores como MacIlwain o Matteucci. El empleo de las armas es materia de gubernaculum, y abarca todo lo que se refiere a las relaciones externas y al orden interno, es decir a lo que, en terminología moderna, se conocerá con el nombre de asuntos de Estado o arcana imperii. Se trata, por su naturaleza, de un poder discrecional, extra legem, y cuyo ejercicio no depende de leyes establecidas, sino que se funda en la prudencia y en la sabiduría del Rey.

Junto al gubernaculum, está la iurisdictio, la cual se concreta en la competencia de administrar la justicia, que es lo que confiere al Rey la cualidad de "soberano". En este ámbito, sí es operativo el límite de la ley. Como fons iustitiae, en cuya virtud el trono es ocupado por el Rey, éste ha de pronunciarse, por sí o por delegación, secundum legem, erigiéndose en garante de que la resolución de los conflictos resulte ajustada a la ley, puesto que, como hemos visto, "es la ley la que instituye al Rey".

Sobre tales presupuestos se funda también uno de los lugares comunes de la literatura política del medioevo: la distinción entre el rey y el tirano, entre el rey como ministro de Dios, y el rey como siervo del diablo, cuya actuación legitima el tiranicidio. La afirmación apodíctica de san Isidoro de Sevilla, recogida por Matteucci, sintetiza los términos del problema: "Serás Rey si te comportas con justicia; de otro modo, no lo serás"16

La primera plasmación práctica de estas concepciones garantistas aparecerá en la más famosa de las Cartas feudales de todos los tiempos, la Magna Charta Libertatis inglesa de 1215, cuya cláusula 39, como es bien sabido, se pronunciaba en los siguientes términos:

"Ningún hombre será detenido o reducido a prisión, o desposeído de sus bienes, o proscrito o desterrado (...), a no ser mediante el juicio legal de sus pares, y conforme a la ley de la tierra”

\footnotetext{
16 Cfr. in extenso Nicolà Matteucci, Organizzazione del potere e libertà. Storia del costituzionalismo moderno, Turín, UTET, 1988, p. 16.
} 
Una garantía proto-moderna, bien es verdad que válida sólo para los freemen, pero garantía al fin, y que, como nos recuerda Carlyle, iba a ser reconocida también por el rey Alfonso IX ante las Cortes de León de $1188^{17}$.

Que el desposeimiento de bienes había de hacerse con arreglo a derecho era algo tan arraigado en la mentalidad social, que sin el desarrollo de algún sistema de representación hubiese sido imposible recabar los recursos financieros requeridos por los crecientes objetivos políticos. La contraposición entre autoridad suprema del rey e indisponibilidad del derecho privado vendría, pues, a explicar que el desarrollo histórico de la libertad constitucional se verificara a través del poder financiero. El axioma de que "concesión de fondos y reparación de injusticias caminan de la mano" - concluye MacIlwain en una obra menos difundida que la dedicada al contraste entre el nuevo y el viejo constitucionalismo - es la llave del moderno desarrollo constitucional ${ }^{18}$; un axioma que el estudioso norteamericano equipara a un aforismo tomado del De Beneficiis de Séneca (Ad Regem enim potestas omnium pertinet; ad singolos proprietas), en el que dicho autor condensa la Veltanschauung política del tardo-medievo.

El proceso de formación del Estado moderno vendrá marcado por el modo en el que se fueron decantando una serie de tensiones mantenidas durante siglos en situación latente: tensiones de carácter externo, con poderes supra-ordenados en la práctica (Papado, Imperio); tensiones internas de tipo feudal y estamental; tensiones también "constitucionales", con la pugna entre el Monarca y las Asambleas; y tensiones, en fin, atinentes a la propia concepción del derecho, bien como agregado de normas legadas por la tradición, o bien como instrumento de gobierno al servicio del poder Príncipe.

\footnotetext{
17 A. J. Carlyle, La libertad política, Méjico, Fondo de Cultura Económica, 1982, p. 31.

18 C.H. Mcllwain, The Growth of Political Thought in the West, Nueva York, Mac Millan, 1932, p. 390.
} 
En una evolución zigzagueante, el derecho pasará a ser el producto de la voluntad racional del Príncipe (auctoritas, non veritas facit legem, según el famoso dictum atribuido a Hobbes); el poder presupuestario de las Asambleas languidecerá en la misma medida en que se fortalece la posición del Rey; y el concepto de soberanía (Rex est Imperator in Regno suo, Superiorem non recognoscens), y la razón de Estado, acabarán por instituir una nueva ordenación que aniquila la tradición del Gobierno limitado, verdadera marca distintiva de un "constitucionalismo" dicho antiguo.

El Estado moderno, como Estado incipientemente absoluto, se nos muestra, pues, como un Estado que alcanza éxito en su pretensión de liberarse de las ataduras del derecho. Puede decirse, con Sartori, que el Estado absoluto es un Estado que se sitúa en las antípodas del Estado constitucional. Es un tipo de Estado legibus solutus o, lo que es lo mismo, un Estado sin límites derivados de la ley, en el que los poseedores del poder se han liberado de los frenos y limitaciones constitucionales ${ }^{19}$.

García Pelayo caracteriza ese conjunto de transformaciones históricas como el tránsito desde una ordenación hacia una organización. La aparición y el desarrollo del Estado exteriorizan, según él, "la tendencia de la época moderna a sustituir la ordenación por la organización en distintos sectores vitales, a sustituir la concepción del orden político como un sistema estático sustentado por la tradición, por un sistema dinámico orientado hacia el futuro" 20 .

Es quizá la apuntada tendencia, de la mano de las transformaciones de toda índole que caracterizan a la modernidad, la que explica la gran paradoja propiciatoria del momento genuinamente constitucional de finales del XVIII. El Estado Moderno, con su configuración del poder sobre la base de la

\footnotetext{
19 Teoría de la democracia, cit., vol. I, p. 239.

20 Manuel García Pelayo, "Hacia el surgimiento histórico del Estado moderno", en Idea de la política y otros escritos, Madrid, Centro de Estudios Constitucionales, 1983, p. 133.
} 
Monarquía, los Consejos, la burocracia, el ejército, la diplomacia y la hacienda, es un potente reductor de antagonismos, cuya dinámica centrípeta y monopolista genera la simplificación reductora que actuará como baza del liberalismo burgués.

Desde el punto de vista del Derecho, puede decirse, en efecto, que la ciencia jurídica moderna es un producto de la burguesía que se construye en modo paralelo al despliegue del Estado absolutista. Tres serían, a juicio de Enrique Gómez Arboleya, los factores decisivos que coadyuvan a tal alumbramiento $^{21}$ :

a) El primero de tales factores es la recepción o "resurección" del Derecho romano. Arropada por el tecnicismo del sistema jurídico romano, la ciencia jurídica moderna postulará la unidad del Derecho y presentará el orden jurídico como un orden sistemático y completo. Unidad política y unidad jurídica actúan así de consuno, generando una técnica interpretativa que se presenta como autónoma con respecto a la sociedad, y que ya no es tributaria del hecho concreto. El Derecho retornará a la Universidad, y el legista, como aliado del Príncipe, dedicará sus esfuerzos a luchar contra la intromisión de los poderes eclesiásticos y las prerrogativas de la nobleza. En este sentido se pronuncia también Van Caenegem, quien en su conocido trabajo sobre los "señores del Derecho", nos recuerda que el common law puede ser presentado como obra de los jueces, el derecho tardo-romano como producto de los profesores, y el derecho revolucionario francés como contribución de los legisladores ${ }^{22}$. Al decir de Gómez Arboleya, esta peculiar concepción de la ciencia jurídica llega hasta Kelsen y sus epígonos, y presenta como caracteres más destacados su racionalismo formal constructivo, su desentendimiento con respecto al sustrato ético y social, y la exaltación del derecho positivo como presupuesto metódico.

21 Enrique Gómez Arboleya, "Supuestos cardinales de la Ciencia Jurídica Moderna", en Estudios de Teoría de la sociedad y del Estado, Madrid, Centro de Estudios Constitucionales, 1982, pp. 411 y ss.

22 Rudolf Van Caenegem, I Signori del Diritto, Milán, Giuffrè, 1991, p. 61 
b) El segundo de ellos es la teoría del Derecho natural racional. El derecho natural de corte racionalista busca conceptos neutros y evidentes, que se erijan en atributos del ser humano por el hecho de serlo. Del Humanismo a la Ilustración, se va sedimentando una concepción individualista y antropocéntrica. Se va ganando la tortuosa lucha por la tolerancia, que culminará con la afirmación de la libertad religiosa, la "madre de todas las libertades", en la conocida expresión empleada por Jellinek. Mediante la noción de "estado de naturaleza", desde Hobbes a Rousseau, se abstrae al hombre de la sociedad para, a partir de aquél, justificar la mecánica de ésta. El vínculo orgánico que otrora constreñía el individuo a la comunidad salta así en pedazos. Poder y razón, derecho y poder, acabarán, de este modo, por entrelazarse bajo la égida de la idea de libertad racional. El Derecho, con su nota esencial de coacción, podrá al cabo presentarse como el sistema de las condiciones que posibilitan la coexistencia, y el despliegue, de las libertades singulares. La impersonalidad de la ley, expresión de la voluntad racionalista, culmina el edificio.

c) Por último, la recepción de un constitucionalismo tradicional y continuista, como el inglés, es el tercero de los factores apuntados por Gómez Arboleya. La lógica mecánica de la separación de poderes, como técnica organizativa al servicio de la libertad, el Gobierno por la discusión, y un derecho que se pretende situar al margen de la lucha entre partidos, y con respecto al cual se postula la sumisión ciega y mecánica del juez, serán el resultado de la peculiar "lectura" continental de la experiencia inglesa.

\section{Constitución: el auge de la idea}

Durante la antigüedad clásica no llega a plantearse como problema el de la creación de un documento dispuesto para exteriorizar los fundamentos posibles del poder. Y las experiencias jurídicas de la época son por completo ajenas a la idea de un ordenamiento de normas, en despliegue dinámico, a partir 
de tales o cuales enunciados básicos. El Estado Moderno, por su parte, más que producto de un desarrollo "natural" de elementos antiguos, será resultado de cierta quiebra, en lo jurídico y en lo político, provocada por la aparición de inéditas situaciones históricas y novedosos universos conceptuales. Si acaso, como apunta Crossa, las concepciones greco-romanas aportan "savia vital" y cierta auctoritas, a menudo apoyada en interpretaciones sesgadas. Es la Edad Media - nos dice el último autor citado - la que proporciona argumentos para el dogma de la Constitución escrita. Y ello mediante la individualización del contraste entre una concepción "material" de la ley, característica de dicho período, y una concepción subjetivo/voluntarista de la orden jurídica, que proviene de la herencia romana. Un contraste que se resolverá, en términos de sucesión histórica, con el tránsito desde el universalismo cristiano del medioevo al particularismo cerrado del Estado absolutista ${ }^{23}$.

La contraposición irreducible entre una y otra concepción del orden jurídico se intentará reducir con la aprobación de una ley superior y común a las partes en conflicto. Una ley recogida en un documento, que se convierte en garantía de su propia posición suprema, y que actúa como valedora del contenido recogido en ella.

A diferencia de las imprecisas leges fundamentales de la Edad Media (que, de todos modos, tanto se invocarían como palanca del pensamiento anti-absolutista), lo radicalmente novedoso proviene aquí del carácter de la Constitución como "decisión de conjunto sobre el modo y la forma de la unidad política" - lo que Carl Schmitt denomina el concepto positivo de Constitución - una decisión global manifestada a través de un acto del poder constituyente. Esta comprensión de la Constitución se convierte a finales del XVIII y comienzos del XIX en una idea irresistible, tanto en los Estados Unidos de América, como en Europa.

23 Emilio Crossa, "Il concetto di Costituzione nell'antiquità classica e la sua modernità", en Studi di Diritto Costituzionale in Memoria di Luigi Rossi, Milán, Giuffrè, 1952, pp. 97 y ss. 
El concepto de Constitución como globalidad del orden político se ha ido revivificando durante el siglo XVIII. En 1733, la Dissertation upon Parties, de Lord Bolingbroke, nos da, por ejemplo, la siguiente definición tradicional, a la inglesa, del término:

“(...) hablando con propiedad, entendemos por Constitución aquel conjunto de leyes, instituciones y costumbres, derivados de algunos principios fijos de razón, y orientados hacia determinados fines del bien común, que forman el sistema general según el cual ha aceptado la comunidad ser gobernada (...). Y llamamos buen gobierno a aquel en el que la administración de los asuntos públicos es llevada de modo juicioso y de conformidad con los principios y los objetivos de la Constitución".

Un cuarto de siglo más tarde, el suizo Emerich de Vattel, en su Tratado, publicado en 1758, The Law of Nations or Principles of Natural Law, aportará una definición del concepto de Constitución más general y descriptiva:

"La Ley Fundamental que determina la forma en la que la autoridad pública ha de ejercerse es lo que forma la constitución de un estado. En ella puede verse la organización por medio de la cual la Nación actúa como un cuerpo político; cómo y por quién el pueblo será gobernado, y cuáles son los derechos y obligaciones de los que gobiernan. Tomada en su esencia, tal constitución no es más que el establecimiento del sistema de acuerdo con el cual una nación se propone actuar al unísono para alcanzar las ventajas que constituyen el objetivo de toda sociedad politica"

Las connotaciones prescriptivas se añaden pronto, a una y otra orilla del Atlántico, cuando la Constitución se erige en instrumento capital de la lucha revolucionaria. Así, en 1776, la ciudad de Concord, en el Estado de Massachusetts, aprueba una Resolution, donde se recoge el postulado de que "una Constitución, entendida en su recto sentido, implica un conjunto de principios asentados con el fin de garantizar a los ciudadanos el pacífico uso y disfrute de sus derechos y privilegios contra cualquier invasión (encroachment) procedente del Gobierno". 
Y en 1789 el celebérrimo artículo 16 de la Declaración de Derechos del Hombre y del Ciudadano eleva a su máxima cota la intencionalidad combativa que se adhiere al concepto:

"Una sociedad en la que no esté asegurada la garantía de los derechos, ni establecida la separación de poderes, carece de Constitución".

Estamos ante un concepto de tipo voluntarista. Ahora se trata de asegurar y de establecer: unos derechos que se proclaman y unos poderes que se disponen. La Constitución pasa a ser resultado de una volición expresa, que se plasma en un documento escrito y vinculante. De ahí, y sólo de ahí, nos dice un buen conocedor de la historia constitucional, arranca la historia de las Constituciones ${ }^{24}$.

Detrás de la simplicidad aparente de una fórmula como la del transcrito artículo 16 de la Declaración, con su "estilotrallazo", se oculta una tajante línea divisoria: la que separa lo viejo, que se quiere cancelar, y lo nuevo, que se pretende instaurar. La Constitución, si quiere serlo, lleva implícito un fuerte componente prescriptivo. Ha de tener las señas de identidad que se estatuyen; unos signos distintivos que, de paso, condenan como no-constitucional todo el pasado de un régimen absolutista que no se había distinguido precisamente por la tutela de los derechos, ni por la separación de los poderes.

Es esa pretensión de innovación, ese cerrojazo a una historia no constitucional que se quiere cancelar y ese pórtico a la nueva era constitucional, que ahora se abre, la que centrará, a lo largo de la última década del siglo XVIII, y buena parte del XIX, la polémica sobre los fundamentos de cualquier Constitución. Frente al concepto innovador, en el que la Constitución se presenta como el resultado de un acto de voluntad creadora, no dejará de esgrimirse la concepción tradicionalista, con sus diversas variantes.

24 Maurizio Fioravanti, "Costituzione: problemi dottrinali e storici", en Stato e Costituzione. Materiali per una storia delle dottrine costituzionali, Turín, Giappichelli, 1993, pp. 105 y ss. 
Dos obras, escritas la una en diálogo con la otra, expresan, quizá mejor que ninguna otra, dicha contraposición. Las Reflexiones sobre la Revolución francesa, publicadas en 1790 por el inglés Edmund Burke, son una apasionada defensa de la tradición. Las instituciones constitucionales sólo pueden durar, según defiende Burke, si son un reflejo del lento devenir tradicional de la costumbre. Una Constitución es el sistema de relaciones y de pactos sociales que vinculan recíprocamente a las distintas partes constitutivas de un Estado. Los derechos son derechos históricos, asentados en la tradición, y heredados de generación en generación. De ahí las ironías de Burke respecto a las construcciones abstractas, matemáticas y geométricas de los franceses. El orden político tiene que ser, en suma, el reflejo del orden social existente, por más desigual y cargado de tensiones que dicho orden sea ${ }^{25}$. Es decir, lo opuesto a esa pretensión instauradora implícita en la voluntad de una Asamblea única, de carácter soberano, instituida por los franceses.

La obra del norteamericano Thomas Paine, Derechos del Hombre, publicada en 1791, lleva por subtítulo "Respuesta al ataque realizado por el Sr. Burke contra la Revolución francesa". La contemplación racional de los derechos se defiende aquí como la garantía de la estabilidad de las instituciones. La Constitución es un acto de refundación ex novo del orden social y político que echa por tierra las instituciones precedentes $y$ funda unas nuevas, cuya justificación radica precisamente en el respeto a los derechos. "Una Constitución - nos dice el norteamericano en un célebre pasaje de su obra - no es algo que sólo exista de nombre, sino de hecho. No tiene una existencia ideal, sino real; y dondequiera que no se pueda exhibir en forma visible, no existe. Una Constitución es algo que antecede a un Gobierno, y un Gobierno no es más que la criatura de una Constitución". Y apostilla: "la Constitución de un país no es el acto de su Gobierno, sino del pueblo que constituye su Gobierno.

25 Edmund Burke, Reflexiones sobre la Revolución francesa, Madrid, Centro de Estudios Constitucionales, 1978, passim. 
Es el cuerpo de elementos al que cabe remitirse y citar artículo por artículo (...)"26.

Adicionalmente, puede señalarse que un tono aún más burlesco que el empleado por Burke con respecto a la pretensión constitucionalista/voluntarista francesa, se advierte en la glosa de la voz "Constitución", escrita en 1792 por otro inglés, Arthur Young, para el Oxford Dictionary: "es un término nuevo que (los franceses) han adoptado y que utilizan como si la constitución fuese una torta elaborable conforme a una receta" (they use it as if the Constitution was a pudding to be made by a receipt $)^{27}$.

\section{Revolución, Poder constituyente y escritura constitucional}

El auge de la idea de Constitución, la "torta elaborable conforme a una receta", según la expresión de Young, inaugura, como se ve, algo bien característico de la teoría constitucional hasta nuestros días. Me refiero a las polémicas y a los contrastes entre pares de concepciones alternativas que atañen a la esencia misma del documento constitucional. Frente al modelo tradicionalista, con el acento puesto en la Constitución como resultado de un equilibrio entre los diversos intereses sociales, el modelo voluntarista hace de la representación de individuos iguales, portadores de iguales derechos, su leit motiv. Esto último vale tanto para la versión francesa de Constitución como para la versión norteamericana.

Pero, a partir de ahí, las parejas de contrastes comienzan con la misma contraposición entre el espíritu de las dos grandes revoluciones de finales del XVIII, la francesa y la norteamericana. Ambas coinciden en su punto de partida: se trata de arrumbar el pasado mediante el ejercicio expreso de un poder dicho constituyente, que cuaja en un documento escrito.

26 Thomas Paine, Derechos del Hombre, Madrid, Alianza, 1984, p. 69.

27 Cit. en Luigi Compagna, Gli opposti sentieri del costituzionalismo, Bolonia, II Mulino, 1998, p. 11. 
En los Estados Unidos de América, años antes de que el abate Sieyés difundiera en Francia su célebre opúsculo sobre el Tercer Estado, se llevó a la práctica la concepción de un poder constituyente, en manos del pueblo, y claramente diferenciado del poder legislativo ordinario. La intuición de fondo de quienes formaron parte del Congreso Continental, representativo de las ex colonias inglesas, en la que se aprobó la Declaración de Independencia, fue darse cuenta de que una Constitución digna de tal nombre no podía ser la mera expresión de una contingente decisión política, puesto que también las revoluciones deben inclinarse ante la supremacía de la ley. Advirtieron, dicho con otros términos, que por muy "supremo" y "desvinculado" que el poder constituyente se presentara, necesitaba también legitimarse mediante un acatamiento a las formalidades y a las exigencias de un procedimiento legal ${ }^{28}$.

El poder constituyente habitará así desde el principio en los intersticios de una relación fluida entre el derecho y la política, presuponiendo por su misma existencia un "Derecho" dispuesto a reconocer su origen en una explícita voluntad inicial, pero también, y de manera imprescindible, una voluntad política capaz de rendir tributo a la necesidad de una fuerte disciplina normativa de impronta constitucional ${ }^{29}$.

Con la aportación de Sieyés, la concepción clásica del poder constituyente, como gran legislador colectivo, encuentra su más articulada expresión. Como es sabido, Sieyés profundiza en el concepto de representación, distinguiendo entre representantes ordinarios y representantes extraordinarios. Aquellos tienen un poder limitado a la gestión de los asuntos de gobierno. Éstos forman un genuino poder constituyente: "como una gran nación no puede estar reuniéndose cada vez que así lo exijan

\footnotetext{
28 Cfr. Matteucci, "La Costituzione Statunitense e il Moderno Costituzionalismo”, en Tiziano Bonazzi, ed., La Costituzione Statunitense e il suo significato odierno, Bolonia, II Mulino, 1988, pp. 29 y ss.

29 Mauricio Fioravanti, "Potere costituente e Diritto Pubblico", en Stato e Costituzione..., cit. p. 56 .
} 
circunstancias excepcionales, hay que delegar en representantes extraordinarios los poderes necesarios para hacer frente a tales circunstancias". La Asamblea ordinaria aprobará las leyes ordinarias; la Asamblea extraordinaria, las leyes constitucionales. Estas últimas poseen dos características: regulan la vida y la modalidad de acción de la representación ordinaria, que queda así expresamente vinculada, y al mismo tiempo expresan plenamente la voluntad de la Nación, origen de toda legalidad. La Asamblea constituyente es, pues, la fuente de todos los poderes. Es la Nación sin mediaciones ${ }^{30}$.

Una construcción doctrinal semejante todavía es presentada hoy como el "paradigma de la teoría jurídica continental sobre la Constitución" 31 . Esto es así cuando menos por tres órdenes de razones:

a) porque, con su definición de la relación entre pouvoir constituant y pouvoirs constitués, Sieyès sienta las bases de la moderna teoría constitucional. La Constitución pasa a ser un acto normativo que define y disciplina el ejercicio del poder soberano.

b) porque delimita, de la manera más expresiva, el contraste entre la teoría democrática del poder constituyente, y la teoría antidemocrática de la representación, en la cual se basará toda la práctica del Estado liberal de Derecho durante el siglo XIX.

c) y por último, pero no menos importante, porque Sieyès realizará la más decisiva contribución en una materia de tanta trascendencia como la reforma y el cambio de Constitución, afrontando en términos jurídicos la cuestión de la sucesión de las Constituciones.

\footnotetext{
30 Enmanuel Sieyès, Qué es el Tercer Estado, ed. de Francisco Ayala, Madrid, Aguilar, 1973, passim.

31 Cfr. el ensayo de Pier Paolo Portinaro "II grande legislatore e il custode della Costituzione", en Zagrebelsky, Portinaro y Luther, eds., I/ futuro della Costituzione, Turín, Einaudi, 1996, pp. 5 y ss.
} 
No es necesario insistir mucho en las paradojas y contradicciones inherentes a una fórmula como la del poder constituyente. Revolución (en el sentido de poder constituyente) y Constitución (como producto o resultado del ejercicio de éste) se nos muestran en contraposición irreductible. Si sobrevive la Revolución, entonces la Constitución viene contradicha y "ninguneada"; si es la Constitución la que se asienta, será la Revolución la que puede darse por cancelada, puesto que la Constitución se establece para siempre. Algunas aportaciones despliegan notable erudición para denunciar toda la inconsistencia lógica escondida tras la funcionalidad de un concepto como el de poder constituyente. "Henos aquí, nos dice, por ejemplo, Negri, ante una extrema paradoja: un poder que surge de la nada y organiza todo el derecho. Una paradoja que, precisamente por su carácter extremo, resulta insostenible. Nunca como a propósito del poder constituyente se ha ejercitado la ciencia jurídica en aquel juego de afirmar y negar, de absolutizar y limitar que, por otra parte, es característica de su desarrollo lógico"32

Paradojas y contradicciones que no se manifiestan sólo en el plano de la lógica subyacente a él, sino también en el de la secuencia temporal de su propio despliegue:

"La historia constitucional es cambio, contingencia política, acumulación en el presente de experiencias del pasado; es realidad social, relación entre el pasado y el futuro, movimiento de sujetos imposibles de definir a priori, imposibilidad de previsión de problemas y espontaneidad de soluciones. Por contra, el poder constituyente consiste en la fijación y absolutización de valores políticos; es un puro deber ser, una recreación ex novo, que omite el pasado y reduce al presente todo el futuro; es en su principio una inesperada aceleración histórica, y sucesivamente un frenazo (...)"33

\footnotetext{
32 Antonio Negri, El Poder Constituyente. Ensayo sobre las alternativas de la modernidad, Madrid, Libertarias, 1994, p. 18.

33 Gustavo Zagrebelsky, "Storia e Costituzione", en la obra colectiva ya citada /l futuro della Costituzione, pp. 35 y ss.
} 
Tomemos, pues, a beneficio de inventario la herencia de un concepto tan emblemático para la teoría constitucional como el poder constituyente, verdadero mito fundacional que reformula más técnicamente, y la hace operativa, la idea ilustrada del contrato social, y detengámonos en otro de los rasgos compartidos por las revoluciones norteamericana y francesa: el de la (novedosa) articulación de la Constitución en un documento escrito.

Según una opinión bastante acreditada, las revoluciones norteamericana y francesa, al condensarse en un documento escrito, al que llamaron Constitución, tuvieron el efecto de aunar los dos significados del término que habían predominado hasta entonces: lingüístico-jurídico el uno (Constitución como orden jurídica de un determinado carácter); y ético-político, o iusnaturalista, el otro ${ }^{34}$.

La Constitución vendrá a ser en lo sucesivo un texto jurídico que establece el modo de ser político de un Estado. La interpenetración de terminología política y terminología jurídica, que se hace operativa en el texto constitucional, expresa la intención de asentar jurídicamente el orden político. Y el valor último de un empeño semejante, radica justamente, al decir de Luhmann, en el objetivo central de cualquier Constitución: reducir la contraposición entre el mundo de la política y el mundo del Derecho, vinculando ambos a una cepa común de la cual proceden ${ }^{35}$. Según Luhmann, mientras que en Francia el ascendente de las instituciones inglesas hizo que el núcleo del debate constitucional versara sobre la redistribución de los poderes, en los Estados Unidos de América, el énfasis se puso, ya ab initio, en el valor intrínseco de un documento cerrado, auténtico germen para la distinción entre la Constitución y el resto del Derecho ${ }^{36}$.

\footnotetext{
34 G. Stourth, "Changing Meanings of the Term from the Early Seventeenth to the Late Eighteenth Century", en T. Ball y J.G. Pocock, eds., Conceptual Change and the Constitution, Boston, Lawrence Kass, 1988, pp. 32 y ss.

35 Niklas Luhmann, "La Costituzione come conquista evolutiva", en la obra colectiva ya citada Il futuro della Costituzione, pp. 83 y ss.

36 Con respecto a Francia, estudia al detalle el asunto la clásica obra de Duguit La separación de poderes y la Asamblea Nacional de 1789, edición al cuidado de Pablo Pérez Tremps, Madrid, Centro de Estudios Constitucionales, 1996.
} 
En Norteamérica, se trataba de crear una orden jurídica que actuara como regla de colisión, tal y como intuyó Hamilton en el célebre fragmento 78 de $E l$ Federalista, bajo la rúbrica "El Departamento Judicial":

"Las limitaciones de esta clase [impuestas al poder legislativo] - escribe Hamilton - no pueden preservarse en la práctica por otra vía que la de los tribunales de justicia, cuyo deber será declarar nulas todas las leyes contrarias al sentido manifiesto de la Constitución. Sin ello todas las reservas que se realicen respecto a determinados derechos o privilegios quedarán en nada".

Y todavía de forma más enérgica:

"Una Constitución es de hecho una ley fundamental y así debe de ser considerada por los jueces. A ellos pertenece, por lo tanto, determinar su significado, así como el de cualquier ley que provenga del cuerpo legislativo. Y si ocurriere que entre las dos hay una discrepancia, debe preferirse, como es natural, aquella que posee fuerza obligatoria y validez superior; en otras palabras, debe preferirse la Constitución a la ley ordinaria, la intención del pueblo a la intención de sus mandatarios" ${ }^{37}$.

La positivización de una ley que funda todo el Derecho viene a hacer innecesaria, como también apunta Luhmann, cualquier otra norma extrasistémica del estilo de la norma fundamental hipotética kelseniana. Desde este punto de vista, la gran innovación reside en el hecho de que el texto constitucional aporta una solución de tipo jurídico al problema de la autorreferencialidad del sistema político y, al mismo tiempo, da una respuesta de índole política a la cuestión de la autorreferencialidad del sistema jurídico.

Los contrastes entre lo constitucional frente a lo no constitucional, y entre la Constitución escrita y el resto del Derecho - decisivos incluso para la adopción de la palabra Constitución, puesto que ninguna otra de las expresiones equivalentes

37 Cfr., in extenso, Roberto Blanco Valdés, El valor de la Constitución, Madrid, Alianza, 1994, pp. 137 y ss. 
(compact, covenant, fundamental) permitían la elocuente simpleza de la contraposición constitutional/unconstitutional - circulan durante las últimas décadas del XVIII. Y llegan sin solución de continuidad hasta la que es probablemente la más célebre decisión judicial de todos los tiempos: la dictada por el juez Marshall, en 1803, en el caso Marbury contra Madison.

Como de sobra es conocido, el doble carácter de la Constitución, como norma escrita, y como norma primordial (paramount law), vendrá considerado allí como el argumento decisivo en favor de la facultad de revisión judicial de las leyes:

"O la Constitución es una ley suprema, inmodificable por medios ordinarios, o se sitúa en el nivel de las leyes ordinarias $\mathrm{y}$, al igual que esas leyes, puede ser alterada cuando la legislatura desee hacerlo. Si la primera opción de esta disyuntiva es cierta, entonces un acto legislativo contrario a la Constitución no constituye derecho; si es cierta la segunda opción, entonces las Constituciones escritas son proyectos absurdos, por parte del pueblo, para limitar un poder que por su propia naturaleza es ilimitable. Ciertamente, todos los que han construido Constituciones escritas las han contemplado como formando la ley suprema y fundamental de la nación y, consiguientemente, la teoría de cada uno de esos gobiernos debe ser que una ley de la legislatura incompatible con la Constitución, es nula. Esta teoría guarda una relación esencial con la Constitución escrita y, por consiguiente, debe ser considerada por esta Corte como uno de los principios fundamentales de nuestra sociedad"38.

También resulta consustancial al carácter escrito de la Constitución norteamericana algo que ha sido resaltado desde múltiples puntos de vista. Me refiero al aura que cobró pronto el Documento constitucional, equiparable en todo al de una escritura sagrada. El tópico del apego a la Constitución como "religión civil", que pusiera en circulación Tocqueville, con la

\footnotetext{
38 Marbury contra Madison, 1 Cranch 137, 177, subrayado mío. Cfr. Harold Burton, "Marbury v. Madison: The Cornerstone of Constitutional Law", en Jesse Choper, The Supreme Court and Its Justices, Chicago, American Bar Association, 1987, pp. 14 y ss.
} 
bandera, la Declaración de Independencia y el texto constitucional, como la "santa trinidad" de las creencias cívicas norteamericanas, tiene que ver, sin duda, con el carácter simultáneo de la fundación nacional y el proceso constituyente. La Constitución pudo actuar así, desde los inicios de su puesta en práctica, no sólo como un instrumento, sino también como un símbolo, por emplear los términos de un conocido ensayo de Corwin ${ }^{39}$.

Revolución, ejercicio del poder constituyente y Constitución escrita son los verdaderos ritos de paso que transforman un cuestionable constitucionalismo "antiguo" en un constitucionalismo racionalizado, vigoroso y de vocación universal. No obstante la "persistencia del Antiguo Régimen" en bastantes aspectos de la estructura social, magistralmente estudiada por Arnold J.Mayer ${ }^{40}$, lo que interesa destacar es que la evolución del pensamiento y de las formas políticas se realiza desde entonces tomando al Estado constitucional como el polo de referencia del debate. Comparado con la quiebra que una pretensión racionalnormativa, como la encerrada en la Constitución escrita, supuso con respecto a cualquier ordenación anterior, y con respecto al "gran modelo" británico, todos los cuestionamientos "restauradores", y las denuncias combativas en favor de una más acabada correspondencia entre la formalización jurídica del fenómeno del poder y su efectivo despliegue, no alcanzan más que una importancia de segundo orden. Incluso el planteamiento de alternativas radicales - el bolchevismo y los fascismos - a partir de la Primera Gran Guerra se realizará en diálogo explícito con el pensamiento de impronta constitucional.

39 "The Constitution as Instrument and as Symbol", American Political Science Review, 30 (1936), pp. 1071 y ss.; cfr. Michael Kammen, A Machine that would go by Itself. The Constitution in American Culture, Nueva York, Alfred Knopf, 1986, Cpt.3 ("All that gives us a National Character"). Desarrollan in extenso el argumento las obras de Sanford Levinson Constitutional Faith, Princeton, Princeton Un. Press, 1988, y la de Robert Bellah, The Broken Covenant. American Civil Religion in Time of Trial, Chicago, University of Chicago Press, 1975.

40 A. J. Mayer, La persistencia del Antiguo Régimen, Madrid, Alianza, 1981. 


\section{USA frente a Francia: Las razones de una bifurcación}

El constitucionalismo del siglo XIX no fue, como puede serlo hoy, un fenómeno de características compartidas y globales. A una y otra orilla del Atlántico, la coincidencia de presupuestos en torno a unas mismas ideas centrales, no impedirá la aparición de un nítido cisma en el decurso de la práctica constitucional. Del lado del "viejo continente", el constitucionalismo se nos muestra como algo construido a trompicones, un fenómeno discontinuo, en el que el impulso revolucionario de partida se ve refrenado y reafirmado sucesivamente. Una historia, en suma, sacudida por quebrantamientos, compromisos y rupturas. Y del lado norteamericano, no es ajeno al constitucionalismo el trauma de la guerra civil, pero el texto originario, con sus adiciones, continúa siendo, más de dos siglos después, el punto de arranque de un "sendero jurídico" por cuyos márgenes ha discurrido la práctica política hasta nuestros mismos días ${ }^{41}$.

Las razones de semejante bifurcación interesarían tan sólo como reliquia histórica si no fuera porque su legado se ha dejado sentir, hasta hace bien poco, sobre las aproximaciones teóricas - lo que a la postre tampoco tendría importancia decisiva - y sobre la práctica, que esto sí importa, del Estado constitucional.

Ya en el momento de los debates ante la Asamblea Nacional francesa de 1789, la diversa conformación social de los Estados Unidos fue utilizada como argumento para atemperar la fascinación sentida por algunos diputados con respecto al texto constitucional aprobado en Filadelfia un par de años antes.

En la sesión de 31 de agosto de 1789, el diputado LallyTollendal se pronunciaba sobre el particular con un lenguaje que llama la atención por lo incisivo de su positivismo sociológico:

"No pretendemos, en absoluto, establecer una comparación entre Francia y los Estados Unidos de América. Sabemos que

41 Cfr. Bruce Ackerman, We the People. Foundations, Cambridge, Harvard University Press, 1991, pp. 94 y ss. bajo el epígrafe "The Path of the Law". 
esto constituiría un raro abuso del razonamiento y de la palabra, querer juntar dos pueblos y dos posiciones tan diferentes. Por un lado, una República federal formada por trece Repúblicas nacientes, en un mundo nuevo, trece millones de habitantes, es decir, quinientas mil cabezas de familia, casi todos propietarios agrícolas, viviendas dispersas; sin enemigos que combatir, sin vecinos que temer, costumbres sencillas, necesidades limitadas; por otro lado, una Monarquía antigua, en el viejo mundo; veintiséis millones de personas, de las cuales dos millones, a lo sumo, son propietarios de tierras, una población amontonada, siempre con vecinos y con rivales, a menudo con enemigos exteriores; y como enemigos interiores, los prejuicios, las necesidades, las pasiones, y todo lo que de ello deriva, y todo lo que debe ser su freno" ${ }^{\prime 2}$.

Las diferencias abismales en la estructuración social, junto a la convulsa trayectoria de los acontecimientos que se suceden en Francia entre 1789 y el golpe de brumario (el "cierre de la Revolución", para Napoleón) explican que el contraste entre las dos grandes Revoluciones inaugurales de la edad contemporánea, se convirtiera de inmediato en un tópico del pensamiento politológico.

Según relata Negri, la comparación de las dos revoluciones aparece en la presentación de la edición alemana de las Reflexiones sobre la revolución francesa, de Burke, llevada a cabo en 1793 por Friedich von Gentz. Pocos años después, la contraposición de una y otra experiencia revolucionaria fue utilizada por el entourage de John Adams, en la campaña presidencial de 1800, en oposición a Jefferson. Frente al terror jacobino, frente a la revolución como una marea abstracta e ideológica que arrasa con todo, la Revolución norteamericana podía presentarse como un remanso de orden y concreción, fundada en el respeto y el desarrollo de las libertades ${ }^{43}$.

42 Cfr. Leon Duguit, La separación de poderes y la Asamblea Nacional de 1789, cit., p. 19.

43 Cfr. Antonio Negri, El Poder Constituyente..., cit., p. 34. 
En tiempos mucho más próximos, la célebre obra de Hanna Arendt, On Revolution, publicada en 1963, da cierto empaque teórico a la cuestión, convirtiendo el eje central del discurso no ya en lo abstracto de la Revolución francesa frente a lo concreto de la Revolución norteamericana, sino en la diferencia profunda que permite discernir lo que es una revolución politica (la última de las citadas), frente a una revolución social como la francesa ${ }^{44}$.

La revolución politica trasciende lo social, sin aniquilarlo, dando lugar a un nivel de síntesis, en el que el equilibrio y la cooperación generan un espacio público de libertad. La revolución social, y en particular la francesa, subordina, por el contrario, el ámbito de lo político al ámbito de lo social. Abandonado de esta manera a su suerte, lo político gira en el vacío, en una búsqueda de libertad que se va convirtiendo cada vez en más ciega y enloquecida. "Allí donde lo político - resume de nuevo Negri - no permite a la sociedad comprenderse y constituirse en la comprensión, allí imperarán la locura y el terror; allí el totalitarismo no podrá sino llevarse la mejor parte".

En polémica con la tesis de Arendt, construye también su hipótesis explicativa otro gigante de las ciencias sociales, Jürgen Habermas, quien sustenta su modo de ver las cosas en la diferente interpretación del Derecho Natural expresada por las dos revoluciones: una, la francesa, asume el Derecho Natural como un ideal que es preciso realizar; la otra, la norteamericana, como un estado ya existente, y sobre el que la intervención política no puede más que producir efectos perturbadores. Es decir, algo bien distinto - rectius: lo opuesto, al excluir la necesidad de política del caso norteamericano - de lo que defiende Arendt, por lo que la teoría del autor germano ha sido calificada como "inversión de la tesis de las dos revoluciones" ${ }^{45}$.

\footnotetext{
44 Hanna Arendt, On Revolution, Londres, Faber and Faber, 1963.

45 Habermas, "Diritto Naturale e Revoluzione", en Prassi politica e teoria critica della società, Bolonia, II Mulino, 1973, apud Negri, El Poder Constituyente..., pp. 39 y ss., y 213 y ss.
} 
Desde la teoría constitucional, resulta en cualquier caso ineludible aportar razones que expliquen, en lo posible, la bifurcación de caminos emprendidos por el constitucionalismo a partir de las dos experiencias revolucionarias.

En la misma estela de la aportación habermasiana, se ha resaltado, por ejemplo, que Francia y Norteamérica reflejan dos concepciones bien distintas en el propio modo de entender los fundamentos de la Constitución. Dos concepciones que están ya presentes, la una detrás de la otra, en dos de los grandes documentos constitucionales de la Inglaterra del XVII: el Agreement of the People (1647), y el Instrument of Government, de Cromwell (1653). El primero refleja la idea de la Constitución como contrato de los "consociados", un texto ("Constituciónalma”, lo llama Portinaro) que viene a institucionalizar un orden que ya existe (un ordine che c'è già), lo que sería el caso de la Constitución norteamericana. En el Instrument, en cambio, se nos muestra la idea de la Constitución como decisión, como acto consciente de creación de una maquinaria de gobierno dispuesta para generar un estado de cosas todavía inexistente (un ordine che non c'è ancora ${ }^{46}$.

Fioravanti, por su parte, profundiza también, como Habermas, en las diferencias que se derivan del diverso modo de entender el Derecho Natural como fuente inspiradora. En el caso de los Estados Unidos, se trata de un Derecho Natural de corte clásico; en el de Francia, de un derecho Natural rediseñado como Derecho Natural racional.

a) El Derecho Natural clásico viene a ser algo muy semejante al derecho histórico que, con tanta insistencia, defiende Burke (distinción entre el Rey y el tirano, legitimidad del derecho de resistencia, etc.). La novedad con respecto a Burke radica en que la tradición inglesa, como fuente explícita de inspiración, es sustituida por una apelación al Derecho Natural intensamente influida por el pensamiento europeo $\mathrm{y}$, en particular,

46 Portinaro,"Il grande legislatore e il custode della Costituzione", cit. 
por la obra de Locke. De éste, los constituyentes de Filadelfia toman, sobre todo, la idea de la ley natural del intercambio y la aprobación. Es decir el "individualismo posesivo", por decirlo según el conocido título de la obra de C.B. McPherson. Una sociedad tan homogénea como la norteamericana de la época, casi naturalmente burguesa, a la que le eran ajenos los problemas de la emancipación de las viejas formas feudales de dominio, y de lo que más tarde se llamaría la "cuestión social", una sociedad donde resultaba en extremo sencillo la adquisición de la propiedad y de la tierra, no necesitaba un proyecto político fuerte, como el que plasma la Revolución francesa. En los Estados Unidos bastaba con ponerse a resguardo de la nefasta influencia del legislador tiránico. Y para ello, el "viejo" Locke del derecho de resistencia, y el "nuevo" Locke del individualismo posesivo, era lo más funcional. No hay allí, en suma, un momento político que concilie voluntades con fines prospectivos, y que pueda distinguirse de la acción de defensa y tutela del derecho ya existente. "El antiguo derecho de resistencia - concluye Fioravanti - actúa al unísono con la moderna primacía de la sociedad civil económica, dejando a la vieja Europa la primacía de la política como proyecto prescriptivo y colectivo con fines de largo alcance" 47.

b) En Francia, es sólo con un Derecho Natural modernizado, de impronta racionalista, como se puede elaborar ese proyecto político al que acabamos de referirnos. Aquí se trata no sólo de apelar a unos vaporosos fundamentos filosóficos, sino también de convertirlos en derecho positivo mediante la proclamación de los derechos del hombre. Esta dimensión de la revolución como saldo de cuentas con el pasado, como conflicto global entre dos sistemas del todo opuestos, en valores políticos y en dimensión constitutiva, es la que da su marca distintiva a la Revolución francesa. Y es también la que permite presentarla como la revolución por antonomasia de los tiempos modernos.

\footnotetext{
47 Maurizio Fioravanti, “Costituzione: problemi dottrinali e storici”, en Stato e Costituzione..., cit., p. 126.
} 
La Constitución se convierte así en un proyecto contra lo antiguo. Un proyecto que crea, porque necesita de él, un nuevo sujeto soberano y fuerte, capaz de expresar la voluntad general, y de utilizarla como arma de combate frente a los enemigos tradicionales y los adversarios nuevos. Si en los Estados Unidos el Derecho Natural se invoca, aquí se proclama, con el preciso objetivo de concitar la adhesión (que de todos modos se da por supuesta) de unos ciudadanos activos, virtuosos e identificados con los ideales de nuevo signo.

Podemos así extraer la conclusión, de gran importancia para nuestro objeto, de que lo que caracteriza a toda Constitución - utilizando ya el vocablo en el sentido plenamente moderno - es su dependencia con respecto a unas determinadas opciones políticas de fondo, que se corresponden, a su vez, con una cierta elección de valores. Tanto en Francia como en los Estados Unidos, la Constitución es el objetivo de la revolución, al mismo tiempo que su límite último. Pero las variantes ideológicas de fondo, punto de partida del empeño constitucional, son las que permiten explicar la bifurcación de caminos del constitucionalismo decimonónico, a que antes nos referíamos.

\section{Las variantes norteamericana y francesa en el ejercicio del poder constituyente. La reforma constitucional y la garantía de los derechos}

En ese sentido, todavía es preciso insistir en dos consecuencias para la teoría constitucional, estrechamente interrelacionadas, y que se derivan de tales variaciones ideológicas: una es la que se refiere al ejercicio del poder constituyente y su corolario, la facultad de reforma constitucional. Otra es la que atañe a la garantía de los derechos.

En lo que se refiere al ejercicio del poder constituyente, la experiencia de los Estados norteamericanos entre 1776 y 1787 muestra una dimensión de aquél con rasgos distintos del que pondrá en práctica la Asamblea Nacional francesa. En Norteamérica, una entelequia como la recogida en la doctrina del 
poder constituyente, se concreta avant la lettre en la atribución al pueblo de una autoridad superior a la de los legisladores. Éstos quedan así despojados del atributo de la soberanía y la ley, como producto de su obra, se subordina a la Constitución, entendida como fuente suprema del Derecho.

Dicho de otro modo, en la experiencia estadounidense, el concepto de poder constituyente se vincula con la idea de rigidez de la Constitución, lo cual da lugar a la presencia de reglas fijas, cuyo plus de estabilidad se garantiza, frente a la voluntad del legislador ordinario, mediante las dificultades de índole formal impuestas para la reforma de aquéllas. El pacto constituyente cuaja en un núcleo de decisión fuerte que se sitúa a resguardo del arbitrio del legislador.

En Francia, poder constituyente y facultades del pueblo soberano para decidir en todo momento sobre las reglas del juego escritas en la Constitución van de la mano. El valor de la Constitución queda, de ese modo, horadado, puesto que lo esencial del poder constituyente es, para los franceses, la formación de una unidad política capaz de expresar su voluntad. Que tal unidad política reciba el nombre de pueblo, o el de Nación, es secundario con respecto a lo que de verdad importa: la centralización de poder en manos de la Asamblea que tal concepción origina. La defensa de la representación de la Nación in toto, realizada de manera tan eficaz por Sieyés, y la asignación a la Asamblea del ejercicio del poder constituyente, resultarán, en tal sentido, decisivas.

La traslación de facultades, desde el poder constituyente soberano, hasta la Asamblea representativa, se hará también notar en el modo de abordar la reforma constitucional. Ésta no se concibe en Francia como un mecanismo de defensa de la supremacía constitucional, sino más bien como medio destinado a salvaguardar la libérrima potestad del poder constituyente para expresar, en todo momento, su voluntad.

"Es precisamente como consecuencia de su omnímoda potestad - dirá el diputado Frochot, refiriéndose al poder constituyente, en la sesión de 3 de septiembre de 1791 - por lo que 
la Nación, consagrando su derecho, se prescribe a sí misma un medio pacífico y legal de ejercitarlo. Lejos de ver en este acto una alienación de la soberanía nacional, yo lo entiendo, al contrario, como una de las más hermosas manifestaciones de su fuerza y de su independencia" ${ }^{48}$.

Frente a la regulación norteamericana de la reforma (mayorías cualificadas en la propuesta y en el proceso de ratificación por parte de los Estados), al servicio de la rigidez constitucional, en Francia el asunto se aborda desde el punto de vista de la necesidad de un "enfriamiento y reconsideración de los posibles excesos pasionales del poder constituyente" ${ }^{49}$.

Y eso en la Constitución de 1791 (artículo 1 del Título VII: L'Assemblée Nationale constituante déclare que la Nation a le droit imprescriptible de changer sa Constitution; et néanmoins, considérant qu'il est plus conforme à l'intérêt national d'user seulement, par les moyens pris dans la Constitution même, du droit d'en réformer les articles dont l'expérience aurait fait sentir les inconvénients, dêcrète qu'il y sera procédé par une Assemblée de Révision...); porque, en 1793, bajo el influjo del "espíritu - Rousseau", por entonces en su apogeo, la inaplicada Constitución girondina anula, lisa y llanamente, cualquier diferencia entre el poder de hacer la Constitución y el poder de reformarla (artículo 28: Un peuple a toujours le droit de revoir, de réformer et de changer sa Constitution. Une generation ne peut assujetir à ses lois les générations futures).

Se delimitan así dos imágenes del poder constituyente, dos funciones del mismo que acabarán por reunirse en el constitucionalismo democrático de nuestros días: una, bajo el influjo de la Revolución francesa, como establecimiento de las opciones políticas básicas, como momento de unificación de voluntades con vistas a la creación de un orden político; otra, bajo el de

48 Cfr. Pedro de Vega, La reforma constitucional y la problemática del poder constituyente, Madrid, Tecnos, 1985, p. 64.

49 Cfr. Jon Elster, "Constitutional Bootstrapping in Philadelphia and Paris", Cardozo Law Review, 14 [1993], pp. 549 y ss. 
la Revolución norteamericana, como fijación de una norma fundamental de garantía, en ausencia de la cual los poderes constituidos, empezando por el propio legislador, se verían libres de límites efectivos.

La primacía histórica de una u otra imagen, en el momento de diseñar el pacto constitucional, no podía dejar de hacerse sentir sobre la cuestión de la defensa de los derechos.

En efecto, la tradición norteamericana es, como se ha dicho tantas veces, profundamente individualista. El proceso revolucionario, puesto formalmente en marcha mediante la Declaración de Independencia de 1776 , encuentra su fuerza motora en la violación por el Parlamento británico de los rights tradicionales de los colonos. Tales derechos, reconocidos antes que proclamados en los textos constitucionales de los Estados, entre 1776 y 1787, preexisten a la Constitución.

Como inberent rights tenidos by nature los define el primer artículo de la Declaración de Virginia, incluída en la Constitución de 1776, con su explícita doble faz de Frame of Government y de Declaration of Rights. El lenguaje no puede ser más expresivo:

"Whereas all Government ought to be instituted and supported for the security and protection of the community as such, and to enable the individuals who compose it to enjoy their natural rights..."

No hay más razón constitucional que el hecho de que todo Gobierno debiera instituirse y mantenerse para seguridad y protección de la comunidad en cuanto tal, y para capacitar a los individuos que la componen en el disfrute de sus derechos naturales. Con pequeñas variaciones de estilo, idéntica amalgama de resonancias hobbesianas y lockianas se encuentra en las Constituciones de Pennsylvania, Vermont, Massachusetts y New Hampshire ${ }^{50}$.

50 Cfr. el expresivo recorrido por los textos que realiza Bartolomé Clavero, Los derechos y los jueces, Madrid, Cívitas, 1988, pp. 19 y ss. La obra contrapone, en Capítulos sucesivos, "América: supremacía de los derechos" frente a "Europa: suficiencia de la ley". 
Si la Constitución federal se entroniza, al cabo, como Supreme Law of the Land es precisamente con el objetivo de situar los derechos a resguardo de veleidades tiránicas, pues la revolución arranca de un memorial de agravios: la aprobación en la metrópoli de la Stamp Act de 1765, tenida por contraria a la tradición impositiva y a los derechos de los colonos. Una forma de actuar que recuerda, dicho sea de paso, al expediente utilizado en 1689 por el Parlamento inglés para condenar la actuación de Jacobo II ("having endeavored to subvert the constitution of the Kingdom by breaking the original contract between King and people... has abdicated the government and the throne is hereby vacant").

Desde tal referente cronológico, hecho explícito por la Declaración de Independencia norteamericana, hasta la aprobación de un Bill de derechos federal, que arranca con la frase Congress shall make no law..., hay una línea de continuidad, cuya lógica es aplastante: el poder legislativo, antes que guardián de los derechos, se ha revelado como fuente potencial de conculcación. Ahora se trata de sujetarle a los dictados de una ley superior, que incluye un reparto de poder, vertical y horizontal, y un reconocimiento de derechos. La visión "judicialista" en materia de garantías es la consecuencia necesaria de todo ello ${ }^{51}$.

La cultura de los derechos de la Revolución norteamericana es individualista, pero también está imbuida de un claro componente historicista o restaurador. Se centra ahí la polémica sobre el carácter continuo o discontinuo de la Revolución norteamericana con respecto al Common law británico.

A la resolución de tal polémica nos parece que contribuye de manera decisiva el estudio de Fioravanti dedicado a las bases históricas de los derechos. A juicio del discípulo de Paolo Grossi, se dan tres grandes modos de fundamentar las libertades

\footnotetext{
51 Cfr. Ulrich Preuss, "The Political Meaning of Constitutionalism”, en Richard Bellamy, ed., Constitutionalism, Democracy and Sovereignity: American and European Perspectives, Aldershot, Avebury, 1996, pp. 11 y ss.
} 
en el plano teórico, a las que corresponden otras tantas formas de reconocimiento y garantía por parte del ordenamiento ${ }^{52}$.

Una es una doctrina individualista y "estatalista" de las libertades, construida en clave anti-historicista (Revolución francesa). Otra es, al mismo tiempo, individualista e historicista (Revolución norteamericana). Por fin, la tercera es historicista y "estatalista", con un fuerte componente anti-individualista (juristas del Estado europeo de derecho del siglo XIX). "Comprender estas combinaciones - dice Fioravanti - significa para nosotros comprender cómo se ha desarrollado, desde la edad de las revoluciones hasta los umbrales de nuestro inmediato presente, la cultura de las libertades..." (Los derechos fundamentales..., p. 25).

A partir de tales modelos, se comprenden, en efecto, mucho mejor las cosas. De un lado, el proceso revolucionario norteamericano, marcado, como hemos dicho, por la desconfianza en el legislador. Un proceso que arranca con las protestas de reestablecimiento de la ancient Constitution británica, vulnerada por obra de una actuación tiránica, y al que posteriormente se añade, cuando la perpetuación de lo anterior se revela imposible, las doctrinas de los derechos individuales y del contrato social, a la búsqueda de una legitimación fuerte y plausible para la separación de Inglaterra (Los derechos fundamentales..., pp. 75 y ss.).

De otro lado, la Revolución francesa, con su pouvoir constituant al estilo ya visto, y con un su sacralización de la ley - legicentrismo, lo llama Fioravanti - que actúa como nexo de unión entre el componente individualista y el componente estatalista de la revolución. Una cultura constitucional capaz de producir la fórmula sintética del artículo 16 de la Declaración, tiene precisamente en la cuestión de la garantía de los derechos su punto más débil y problemático, al fiarlo todo, no sin cierta candidez, a la obra de un legislador virtuoso, que lo es simplemente en tanto que representativo del pueblo o de la Nación,

52 M. Fioravanti, Los derechos fundamentales. Apuntes de historia de las Constituciones, Madrid, Trotta, 1996. 
más allá de las facciones o de los intereses particulares (Los derechos fundamentales, pp. 56 y ss.)

No obstante la identidad aparente en los postulados de principio, consecuencia de ese componente individualista que las dos revoluciones comparten, la "lengua de los derechos" empleada en la Declaración francesa revela la diferencia. Por decirlo en los términos cuantitativos que utiliza García de Enterría, "la declaración cita once veces la palabra 'Ley' y dos más el adverbio 'legalmente'". Y concluye el autor del trabajo cuyo título hemos entrecomillado:

“(...) esta colocación de la Ley en el centro mismo del sistema de los derechos está en el origen de dos fenómenos capitales derivados en línea recta de la Declaración francesa, y que se buscará en vano en la influencia histórica del Derecho norteamericano: la formación del Derecho Público europeo a lo largo de todo el siglo XIX y la reconversión del sistema jurídico en un sistema de Leyes(...). Todo el sistema jurídico queda reducido a un sistema cerrado de Leyes, lo que se llamará el positivismo legalista: la revolución jurídica más radical y más importante de la historia, probablemente" 53 .

A la relación de dichos "fenómenos capitales" con lo que representa ahora el objeto de nuestro tema, es decir, la suerte de la vocación constitucional tras el momento de auge revolucionario, consagramos el siguiente epígrafe.

\section{Falseamiento: las "trampas" del positivismo}

La bifurcación de caminos del constitucionalismo, de que venimos hablando, se transforma, una vez cerrados los tiempos de la comunicación de influencias durante la oleada revolucionaria, en separación y olvido recíproco. No es que falten las miradas - ahí esta la agudísima obra de Tocqueville para atestiguarlo - pero los supuestos de partida, con sus diferencias

\footnotetext{
53 Eduardo García de Enterría, La lengua de los derechos. La formación del Derecho Público europeo tras la Revolución francesa, Madrid, Alianza, 1994, pp. 80-81.
} 
de matiz, producen al poco tiempo prácticas constitucionales que poco tienen en común.

Europa es un laboratorio constitucional, en el que la pulsión política genera un continuo replanteamiento de los grandes problemas de fondo (titularidad de la soberanía, reforma constitucional, disposición de los poderes públicos, etc). Pero tras el tejer y destejer Constituciones, al socaire de los acontecimientos, hay un hilo de continuidad que afecta de lleno al valor de la Constitución y al de la propia doctrina del constitucionalismo.

Uno de los objetivos esenciales del concepto revolucionario de Constitución, la garantía de los derechos, se da por cumplido con la codificación del derecho privado. Éste es un producto sólido y duradero, como también lo será un régimen jurídico de especialidad administrativa, "que permanece", por decirlo con la conocida observación de Otto Mayer. Esto es así hasta el punto de que no es irrazonable poner en tela de juicio el éxito del constitucionalismo, en tanto que idea fuerte de limitación del poder por el Derecho, durante la experiencia europea decimonónica.

La "huída de Constitución" a la hora de positivizar los derechos, esto es en el momento de conferirles efectividad mediante el establecimiento de garantías y mediante la disposición estructural de los poderes, es lo que priva de sentido hablar de un Derecho Constitucional en Europa durante el siglo XIX.

Y a la inversa, la ausencia de esa reducción de los derechos a una esfera civil/privada, la sede constitucional de positivización y garantía de los mismos, propicia en Norteamérica una resolución de "casos y controversias", que se vale de un razonamiento genuinamente jurídico-constitucional.

El mundo del Derecho y el mundo de la Constitución tienden a separase en Europa; las discusiones pasionales de teoría constitucional ceden paso a una teoría rígida y formalista del Estado, que será campo acotado de los iuspublicistas. Un estudioso del fenómeno de la codificación, Giovanni Tarello, mantiene, en términos tajantes, que el constitucionalismo moderno 
aparece en la cultura jurídica con la experiencia norteamericana. Y lo razona así:

"Una estructura organizativa jurídica puede llamarse 'de Derecho Constitucional' (en sentido moderno) cuando presenta tres elementos, a saber: $i$ ) organización del poder político en función de la tutela y garantía de unos derechos asumidos como preexistentes, y con el límite de la inviolabilidad de tales derechos; ii) carácter individual, y no corporativo, de los derechos tutelados; iii) implantación de dos niveles de legalidad jerárquicamente relacionados: la legalidad constitucional y la legalidad ordinaria" ${ }^{4}$.

En la experiencia europea se da, aunque en términos muy matizados el punto $i$ ), pero es muy dudoso que se dé el $i$ ), y falta, desde luego, absolutamente el requisito $\mathrm{iii}$ ).

Tomás y Valiente, en uno de sus escritos publicado con carácter póstumo, contempla el problema de manera más matizada, y en términos de la por él llamada cultura del constitucionalismo:

"Hubo una cultura predominantemente política de la Revolución francesa, y hubo una cultura jurídica de la Revolución americana como sustrato predominante de aquella revolución constitucional. Entre los tres vértices del triángulo formado por Gran Bretaña, Francia y los nacientes Estados Unidos hubo corrientes de pensamiento comunes, como el iusnaturalismo y la doctrina de los derechos naturales. Pero por debajo de influencias circulares entre Francia y la Unión, John Phillip Reid ha puesto de manifiesto la mayor y más profunda relación de dependencia de la culture of constitutionalism norteamericano con la historia tradicional británica y con algunos de sus principios en ella destacados, como su judicialismo y la finura de un sentido jurídico pragmático y casuístico que informa el constitucionalismo anglosajón" $"$.

\footnotetext{
54 Giovanni Tarello, Storia della cultura giuridica moderna I. Assolutismo e codificazione del Diritto, Bolonia, II Mulino, p. 561.

55 Franciso Tomás y Valiente, voz "Constitución”, en Enciclopedia Iberoamericana de Filosofía, vol. 10, Elías Díaz y Alfonso Ruiz Miguel, eds. Tomo la referencia de Bartolomé Clavero, Tomás y Valiente. Una biografía intelectual, Milán, Giuffrè, 1996, pp. 213-214. Por su parte, la
} 
Es la "cultura del constitucionalismo" la que, manifiestamente, languidece en la experiencia europeo-continental del XIX. La idea de los límites del poder queda desplazada por el concepto de una representación nacional como poder omnímodo; la sujeción constitucional de la Nación deviene una "contradicción en los términos", y la Constitución se transforma en documento esencialmente maleable, e incapacitado para encauzar en modo alguno la expresión de la voluntad representativa.

En una ciencia de la Constitución como "biblioteca pendiente de reorganizarse", suele llamarse a esta deriva europeocontinental constitucionalismo de inspiración jacobina, como algo contrapuesto a un constitucionalismo de inspiración anglosajona ${ }^{56}$.

Pero no es el nombre lo que importa. Lo decisivo es que, con el dogma de la omnipotencia del legislador, el componente garantista de la Constitución, y la "idea fuerte" del constitucionalismo, como límite del poder, quedan falseados. La adulteración se verifica a través de diversos frentes:

a) abandonada la idea de límite, la Constitución deja de ser Ley fundamental, y queda degradada a la condición de mero "marco para el ejercicio del poder", una simple exteriorización del modo de ser del poder soberano.

b) el arrinconamiento del componente contractual-individualista, implícito en las construcciones iusnaturalistas de los droits de l'homme, deja a éstos desprovistos de garantía. En la medida en que la Constitución menciona los derechos, si es que lo hace, no son más que mudables autolimitaciones del poder soberano.

c) el Estado con Constitución pasa a ser Estado de Derecho (Rechtsstaat), un Estado que persigue sus fines, y actúa,

referencia de Tomás y Valiente a la obra de Reid lo es, a buen seguro, al monumental estudio de éste Constitutional History of the American Revolution, 4 vols., Madison, 1986-1993.

56 Augusto Barbera y otros, Le basi filosofiche del costituzionalismo, Roma-Bari, Laterza, 1998, pp. 6 y ss. 
sólo de conformidad con el derecho, pero donde los límites se muestran más bien como autorrestricciones revocables.

d) la Constitución deja de ser garantía de unos derechos previos, que se prescriben, para convertirse en descripción del orden institucional. Sólo un correcto funcionamiento de éste permite adicionalmente garantizar las posiciones jurídicas subjetivas atribuidas al individuo por el Estado.

Los distintos frentes a través de los cuales se verifica el falseamiento de la idea constitucional, concretados por Rebuffa en los extremos que, más o menos, acabamos de señalar ${ }^{57}$, son reconducibles, si bien se mira, a un solo término que puede explicarlo todo. Me refiero, claro está, al empeño por hacer operativa una idea que se presenta siempre en conjunción problemática con respecto al constitucionalismo.

Se trata de la soberanía, esa fuerza desnuda, descrita por Bodino como puissace absolue et perpetuèlle, "no limitada ni en poder, ni en responsabilidad, ni en tiempo" 58 , de la que se ha dicho irónicamente que sobrevive, tras sucesivos aggiornamenti, como "un homenaje verbal al carácter democrático-representativo de los sistemas constitucionales de nuestros días" 59.

El ideal constitucional resulta inconciliable con un poder, ni siquiera "dormido", que sea, a la vez, indiviso, incondicionado, ilimitado, y con capacidad para violar, creando uno nuevo, el derecho existente. Según la famosa expresión de Kriele, "la idea de un poder soberano es dinamita revolucionaria para el Estado constitucional" 60 .

El potencial destructor de la soberanía fue apreciado perfectamente en un momento clave de la historia constitucional

\footnotetext{
57 Cfr, G. Rebuffa, Costituzione e costituzionalismi, Turín, Giappicheli, 1990, pp. 43 y ss.

58 Bodino, Los seis libros de la República, Madrid, Tecnos, 1986, Cpt. VIII del Libro Primero.

59 Luigi Ferrajoli, "Beyond sovereignity and citizenship: a global constitutionalism”, en R. Bellamy, ed., Constitutionalism, Democracy and Sovereignity, cit., pp. 151 y ss.

60 Martin Kriele, Introducción a la Teoría del Estado. Fundamentos históricos de la legitimidad del Estado constitucional democrático, Buenos Aires, Depalma, 1980, p. 151.
} 
inglesa. En 1628 correspondió a Edward Coke defender ante la Cámara de los Lores la Petition of Rights en cuya redacción él mismo había intervenido. La Cámara pretendía añadir al Documento una cláusula para proteger la soberanía del Rey, sobre la base de que en sus manos estaba "the protection, safety and happiness of the people". Esto formaba parte del juramento que los Reyes prestaban al acceder al trono (to hold and keep the laws and righteous customs which the community of the realm shall have chosen), con el preciso objetivo de circunscribir la discreción regia al marco de las "antiguas leyes y costumbres". Coke, el juez del célebre caso del Dr. Bonham (1610), en el que el Tribunal se atrevió a poner coto a las facultades del Parlamento ("In many cases the common law will control Acts of Parliament, and sometimes adjudge them to be utterly void: for when an Act of Parliament is against common right and reason, or repugnant, or impossible to be performed, the common law will control it, and adjudge such Act to be void") ${ }^{61}$, tuvo que utilizar ahora sus dotes persuasorias contra las facultades del Rey, y en favor del derecho:

"Sé que la prerrogativa - dijo Coke - es parte del derecho, pero el concepto de poder soberano no forma parte del léxico parlamentario. En mi opinión debilita la Carta Magna y los estatutos; ambos son absolutos, sin ninguna salvedad de 'poder soberano', y si ahora acogemos el concepto estaremos socavando los fundamentos de la ley, y afrontaremos el riesgo de que se venga abajo el edificio entero. Prestemos atención a lo que añadimos. La Carta Magna es algo tan nuestro que no necesita de ningún poder soberano"62.

Parafraseando a Coke, podríamos decir algo muy parecido: una Constitución asentada y en disposición de desplegar su fuerza normativa, ninguna necesidad tiene de la fuerza

61 Cfr. Juan Manuel López Ulla, Orígenes constitucionales del control judicial de las leyes, Madrid, Tecnos, 1999, pp. 30 y ss.

62 Cit. en Arthur Goodhart, Law of the Land. Magna Charta Essays, Charlottesville, The University Press of Virginia, p. 68. 
devastadora un poder soberano. El mal genético de que adoleció el llamado constitucionalismo "de inspiración jacobina" fue la pretensión de conciliar lo inconciliable.

El siglo XIX europeo asiste así a una desintegración del Estado constitucional, sometido a una polarización creciente entre los dos principios de soberanía democrática y soberanía monárquica, que se enfrentan irreductiblemente ${ }^{63}$. Los remedios a dicho mal genético, la soberanía "compartida" de la Restauración, y la entronización del Estado como persona jurídica dotada de voluntad autónoma, serán, al cabo, paliativos poco eficaces, que arrojarán como resultado un largo período de oscurantismo constitucional.

\section{Positivismo versus constitucionalismo}

Junto al pesado lastre de la soberanía, con sus terribles dilemas, un segundo factor que no favorece precisamente la implantación de una genuina cultura constitucional en la Europa del XIX, es el persistente influjo de una concepción de lo jurídico de corte rigurosamente positivista.

Bajo el manto del término "positivismo", se aúnan, como ha mostrado Bobbio, al menos tres doctrinas diferentes ${ }^{64}$. Una primera, parte de la premisa epistemológica de que la ciencia del Derecho, a semejanza de las ciencias empíricas, ha de evitar cualquier sello de índole metafísico en sus fundamentos. La ciencia del Derecho tiene que describir el ordenamiento tal como es, evitando juicios de valor que conduzcan a éste hacia el mundo del deber ser. Se trata, en otras palabras, de la pretensión de construir una teoría jurídica "pura", desbrozada de cualquier elemento espurio. Una segunda doctrina, o cuerpo de doctrinas positivistas, se funda en una representación del sistema jurídico, conforme a la cual el Derecho es un producto de la voluntad humana y, en

\footnotetext{
63 Cfr., de nuevo, Martin Kriele, Introducción a la Teoría del Estado, cit., p. 391

64 cfr. Norberto Bobbio, Giusnaturalismo e positivismo giuridico, Milán, Ed. di Communità, 1972, pp. 103 y ss.
} 
último análisis, de la voluntad del soberano. Por fin, la tercera de las corrientes del positivismo cuaja en una ideología que defiende el derecho positivo como una orden que debe ser acatada, cualquiera que sea su contenido, pretensión que suele presentarse con la caricaturesca fórmula germana Gesetz ist Gesetz.

Cada una de las tres corrientes sucintamente descritas resulta difícil de conciliar, como ha mostrado Troper, con la doctrina del constitucionalismo $^{65}$. La ideología positivista difícilmente puede tener encaje en una doctrina que sólo considera como legítimo al Gobierno constitucional, es decir, uno fundado en determinados principios, y en el seno del cual la obligatoriedad de la orden jurídica se basa no sólo en la conformidad de la misma con respecto a los presupuestos procedimentales recogidos en la Constitución, sino además con la propia conformidad constitucional de sus contenidos.

El positivismo es una teoría del Derecho que critica las diferentes versiones de su doctrina opuesta: el iusnaturalismo. Para éste, por encima del derecho positivo, producto de la voluntad humana, hay un derecho superior, resultado de la voluntad de Dios, o inscrito en la naturaleza de las cosas. Tal Derecho Natural resulta cognoscible a través de la razón, y es competencia de los juristas descubrirlo. Por otra parte, es algo diferente de la moral, y se impone a los destinatarios de la orden jurídica precisamente debido a la conformidad de la orden con los postulados del Derecho Natural.

Tales son los aspectos centrales que el positivismo combate. En su versión más rigurosa, éste sostiene que el Derecho Natural no existe; en sus versiones más moderadas, que no es cognoscible. De un modo u otro, la consecuencia es que hay que atenerse a lo empíricamente comprobado como existente, es decir, un derecho positivo que toma su validez del procedimiento de emisión, y no de su compatibilidad con cualquier derecho superior.

\footnotetext{
65 Michel Troper, Pour une Théorie juridique de l'Etat, París, PUF, 1994, Cpt. XIII («Le concept de constitutionalisme et la théorie moderne du droit»l.
} 
Ya hemos visto que el constitucionalismo aparece, por el contrario, estrechamente vinculado al iusnaturalismo. Se trata de un vínculo histórico, pero también de carácter lógico. Es verdad que la garantía de los derechos, como núcleo de la idea constitucional concretada en un documento escrito, no necesita de ningún Derecho Natural racional para sustentarse. También el positivismo puede defenderlos en la misma medida en que, mediante su reconocimiento explícito, han pasado a ser objeto de las disposiciones constitucionales, esto es, derecho positivo.

Pero hay una cuestión de difícil respuesta desde los postulados positivistas. Se trata de la cuestión del fundamento del carácter obligatorio de la Constitución y, por consiguiente, de los derechos. La Constitución viene a expresar la voluntad del poder constituyente, pero ninguna norma de derecho positivo prescribe tal conformidad. El positivismo se ve así obligado a recurrir a una forma de razonamiento hipotético: si la ley vale porque es conforme con la Constitución, entonces necesariamente hay que suponer que la Constitución es una norma obligatoria. Este es el "salto" operado por la famosa "norma fundamental hipotética" kelseniana, sobre la que habremos de volver. Baste por ahora con decir que el positivismo sustituye una teoría del fundamento del carácter obligatorio del derecho, por una hipótesis acerca de su obligatoriedad.

El constitucionalismo va más allá. La Constitución nace con una vocación de obligatoriedad que es perdurable sobre la voluntad de quienes contribuyeron a su aprobación. Su autoridad se funda en el contenido, no en la voluntad de quienes la aprobaron. Ésta es circunstancial y pasajera; se limita a recoger la voluntad política de un momento - lo que no justificaría la pretensión de validez en el futuro - pero con un contenido que trasciende la voluntad de las generaciones vivas y se dirige a un fin: el de llevar a cabo unos objetivos justos, justos por naturaleza, que pueden concretarse en la salvaguarda de la libertad política. A ese objetivo, que es tanto como decir defensa de la dignidad de la persona y de su libre autodeterminación, se 
enderezan las disposiciones de estructura de la Constitución, así como las referentes a sus principios "dogmáticos".

El constitucionalismo se afirma, pues, como prescripción, y la superioridad de la Constitución, el fundamento de su validez, radica precisamente en su pretensión de instaurar un orden justo. Como dice esquemáticamente Matteucci, es en la "ciceroniana" recta ratio, y no en la "bodiniana" puissance, donde radica el fundamento último de la orden jurídica ${ }^{66}$.

El mismo autor, con largo tracto histórico, describe la suerte política del positivismo en los siguientes términos:

"El positivismo jurídico representará justamente la toma de conciencia de una nueva realidad emergente: el Estado soberano (...). El positivismo jurídico es ciencia en la medida en que, para él, todo se concentra en la ley, un nuevo hecho. Y es también ideología, en cuanto que confiere a la ley una posición privilegiada: la de fuente de las fuentes. La toma de conciencia del Estado moderno es históricamente actual y políticamente vital, pues proporciona a los hombres la necesaria autoconciencia crítica de su tiempo, y los instrumentos políticos y científicos para actuar sobre éste. Para llegar a esto fue necesaria una profunda revolución espiritual, cuyas raíces pueden ser de índole teológico-religioso. Pero el tránsito desde una concepción racionalista de la justicia a una voluntarista se iniciará con aquellos juristas que empiezan a ver en las todavía escasas leyes del Rey o del Parlamento no 'declaraciones de voluntad' que hay que interpretar hacia el fin de la justicia, sino mandatos que es preciso analizar de una forma lógica. Este tránsito llega a su cumbre en la compleja fase de las codificaciones (...) y toca el fondo de la parábola descendente hoy, cuando la ley ha perdido sus antiguas características y ha pasado a ser expresión de una voluntad puntual y contingente, de manera que no se gobierna según la ley, sino que se gobierna legislando".

66 Nicola Matteucci, "Positivismo giuridico e costituzionalismo", Rivista Trimestrale di Diritto Procesuale Civile, 1963, pp. 985 y ss. 
Lo extensísimo de la cita creo que está justificado por la expresividad con que aparecen condensados varios siglos de avatares de pugnas políticas y teorías del Derecho. Corresponde ahora contemplar un poco más de cerca el momento de la apoteosis del positivismo, con sus dogmas (primacía de la ley, ausencia de límites jurídicos al poder soberano, reducción del juez a una máquina dispensadora de silogismos, etc.), y su materialización en una fórmula, la del Estado de Derecho, a cuyo socaire cobrará carta de naturaleza nuestro Derecho Público. 